تأثيركيمياويات مطروحات مختبرات المستثفيات على كفاءة المعالجة البايولوجية لمياه الفضلات

طارق احمد محمود

استخاذ
زينة فخري اسماعيل

مـدرس مســاعد

$$
\text { البيئة والسيطرة على التلوث }
$$

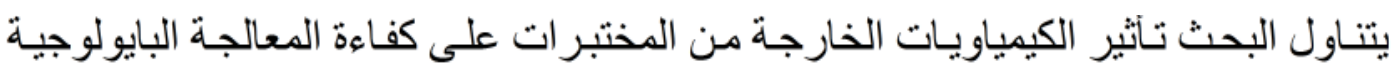

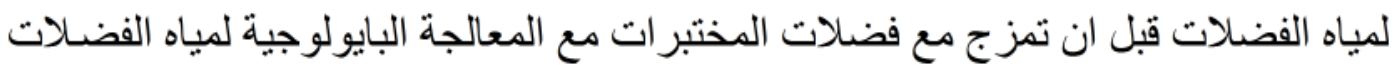

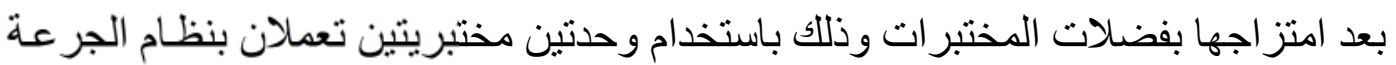

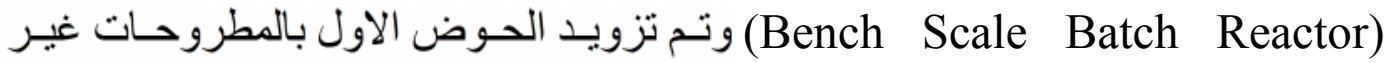

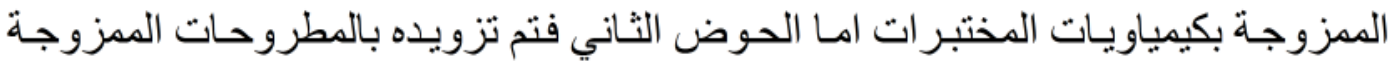

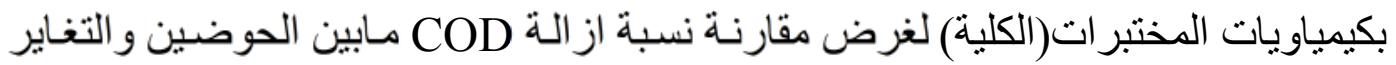

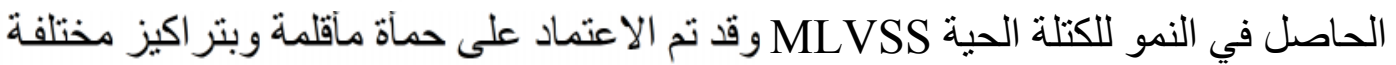

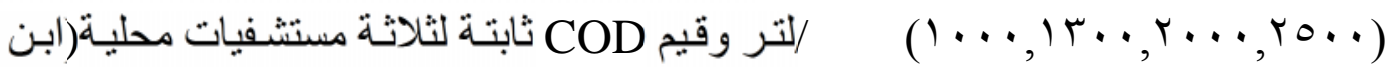
سينا ،ابن الاثير ،الخنساء) .و اظهرت النتائج ان اعلى نسبة از الة للمو اد العضوية تحدث

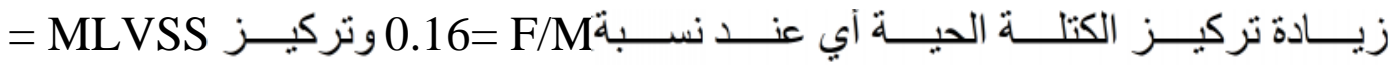

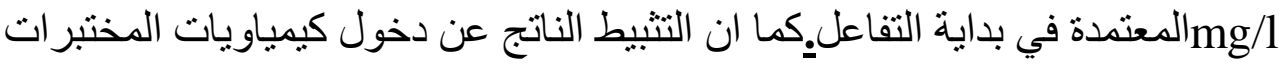

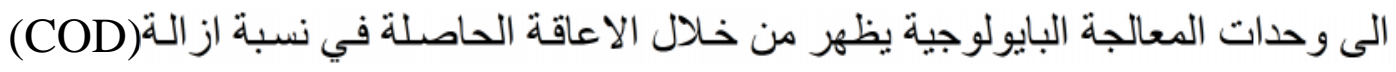

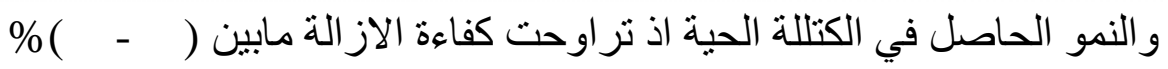

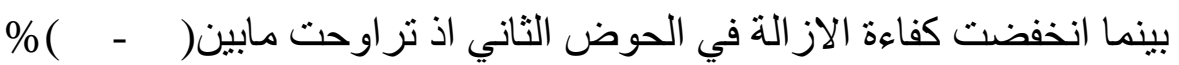

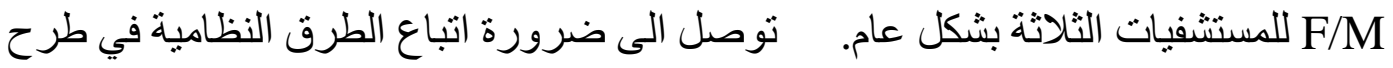

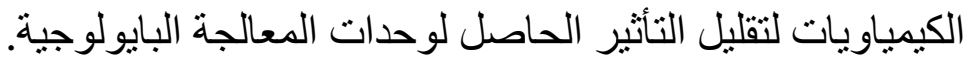

(المعالجة البايولوجية لمياه الفضلات معالجة فضلات المستشفيات بايولوجياً) :

\title{
Effect of hospital laboratory chemical effluents on the effecincy of biological treatment of waste water
}




\title{
Assist.prof
}

Assist.

lecturer

\section{Environmental and pollution Control center}

\begin{abstract}
This paper focuses on the effect of laboratory chemicals on the efficiency of the biological treatment of wastewater for effluents mixed with laboratory waste and other unmixed with it, Two bench scale batch reactor were used .The first reactor feeded with effluents without chemicals, the second reactor feeded with effluents mixed with chemicals, in order to compare the removal rate of (COD) and the growth of (MLVSS) according to concentration of (MLVSS) $(1000,1300,2000,2500) \mathrm{mg} / \mathrm{l}$ at fixed value of (COD)for three hospital(Ibn seena,Ibn alatheer,Alkhansaa) .The result showed that the highest value of removal achieved at $(\mathrm{F} / \mathrm{M}=0.16)$ and $(\mathrm{MLVSS}=2500)$ that in depended at the first of reaction ,also showed that the inhibition effects because of laboratory Chemicals appears through inhibition in the removal of (COD) and growth of (MLVSS).The removal efficiency was about (93-96)\%for the first reactor and about (85-90)\% for the second reactor .Its also showed that its very necessary follow regular ways in order to reduce its effect on the biological treatment unit. kevyords:(biological treatment of wastewater $2005 / 11$ piog treatment of hospital wastewater)

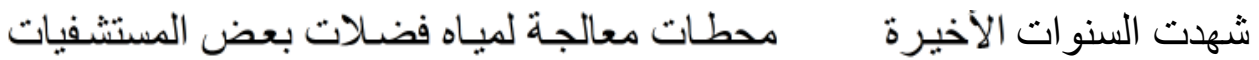

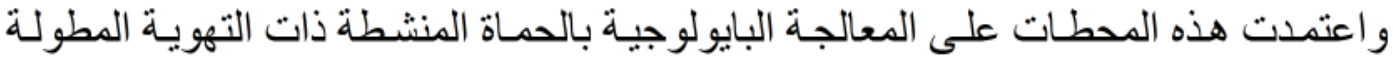

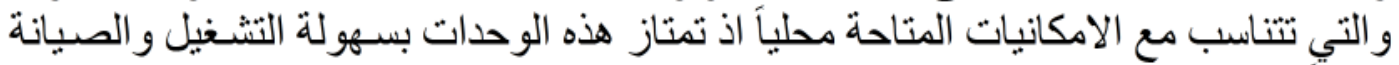

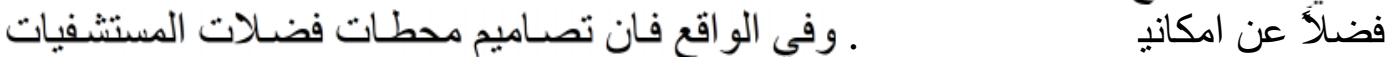

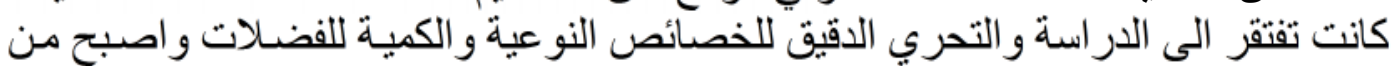

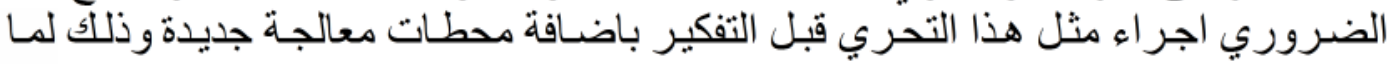

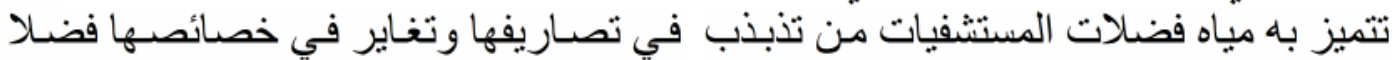

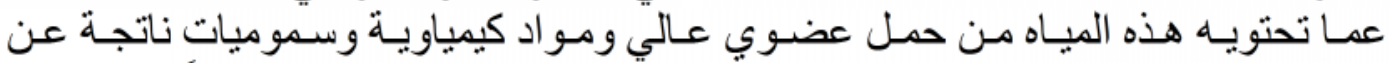

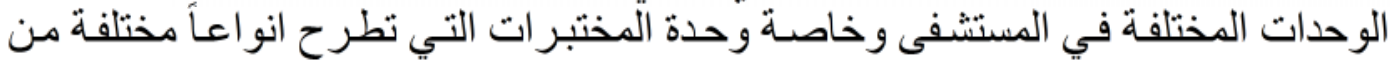

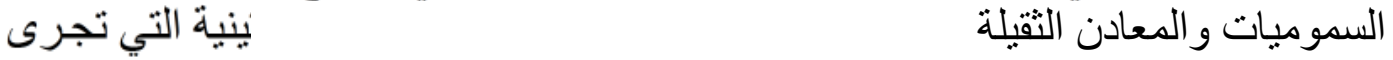

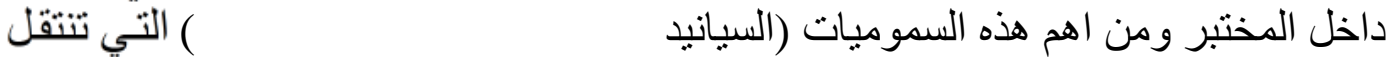

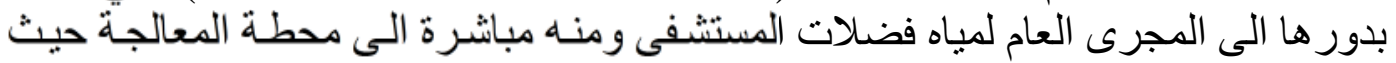

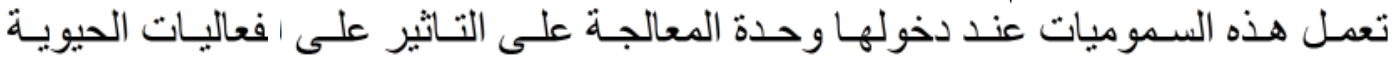

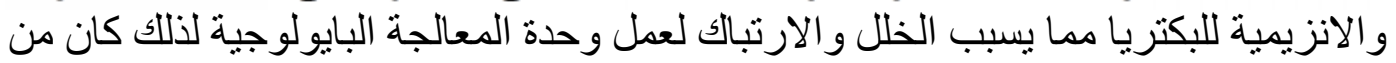


الضروري التعرف على الوحدات الاكثر تلوثـا وخطورة في التاثثر على سير العمليات

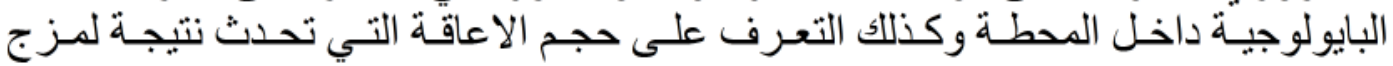

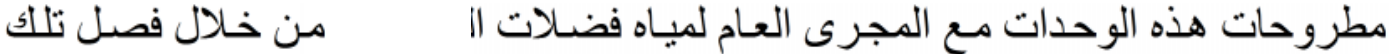

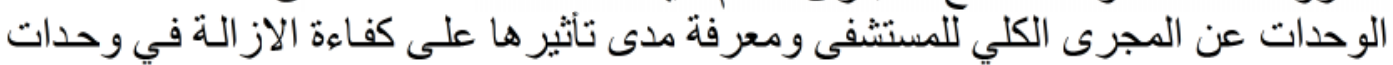
المعالجة البايولوجية لمياه الفضلات.

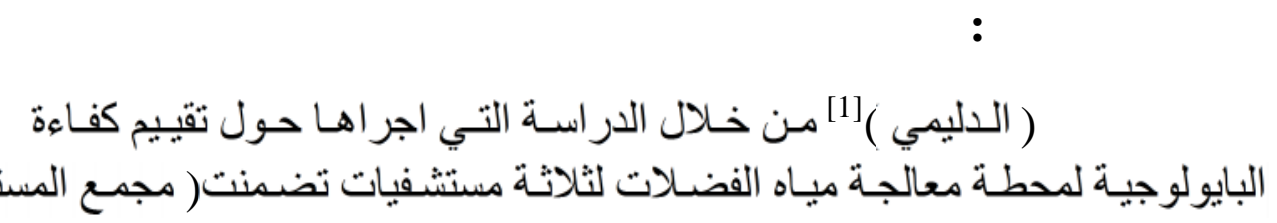

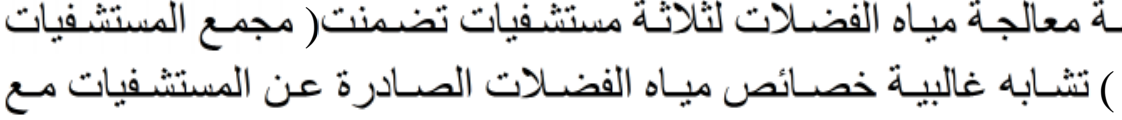

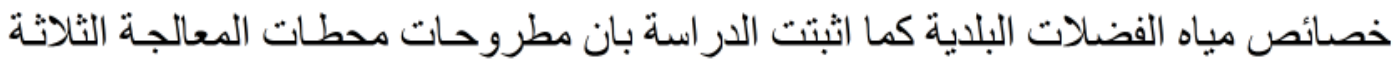

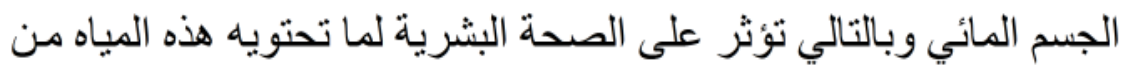

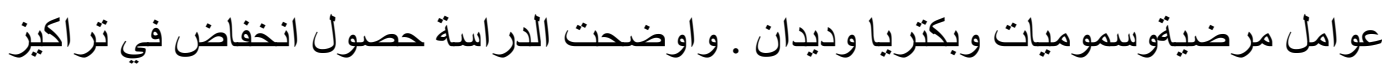

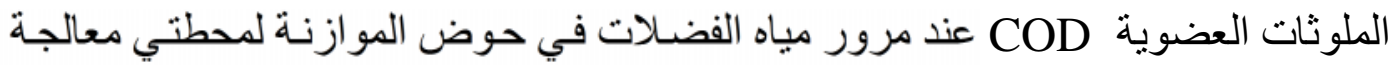

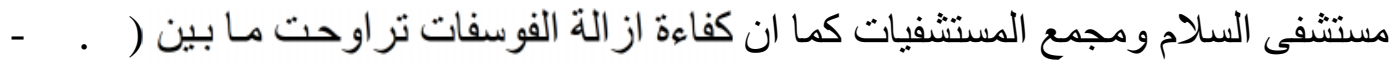

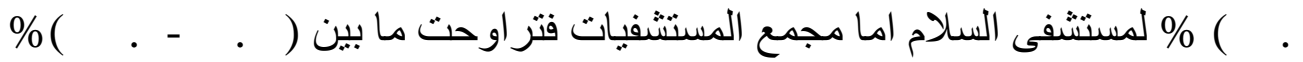

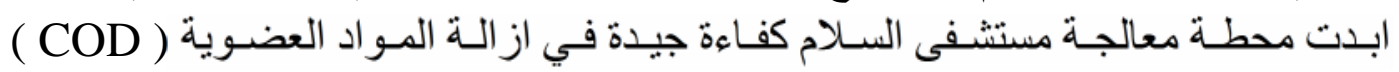

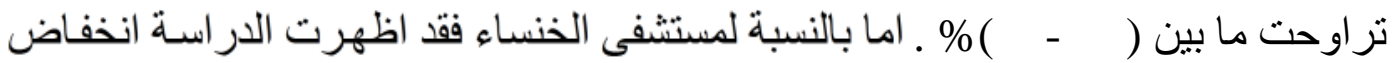

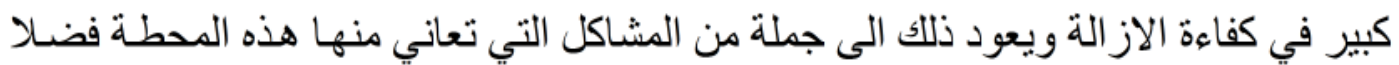

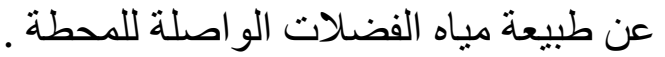

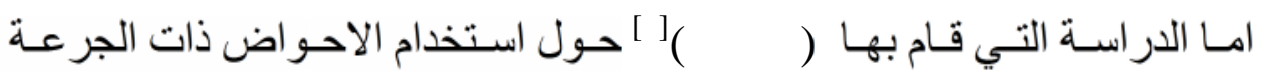

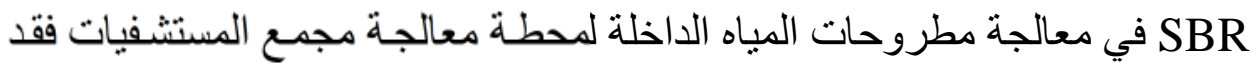

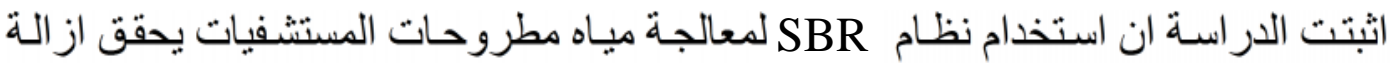
جيدة للمو اد العضوية COD , BOD خلال فترة قصبيرة نسبيا وقد ازداد معدل از الة الة المواد

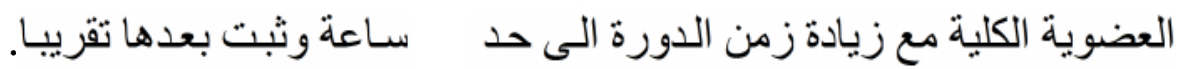

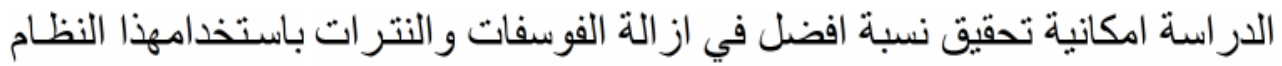

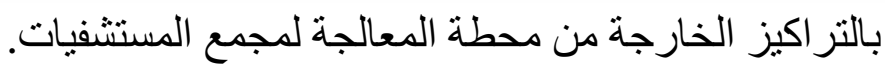

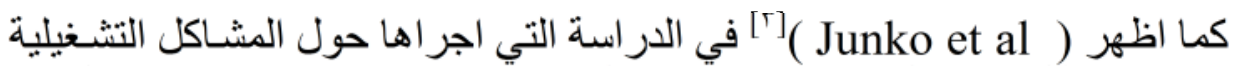

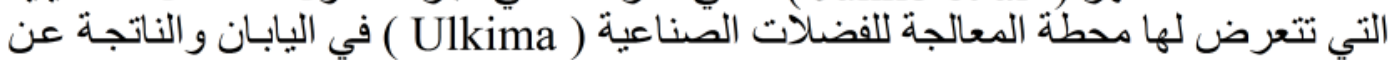

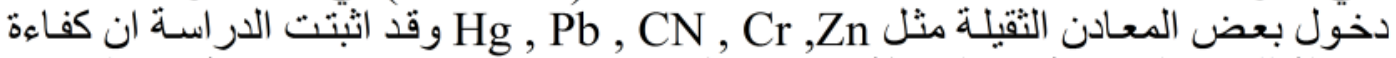

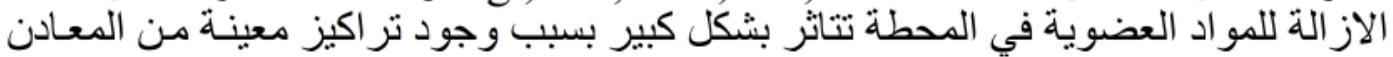

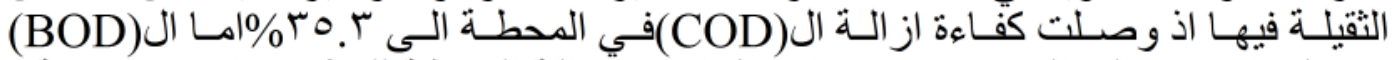

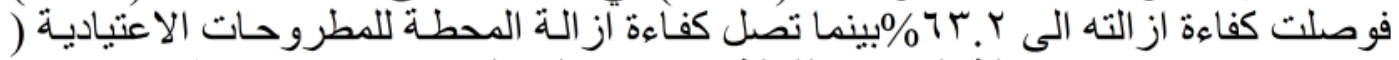

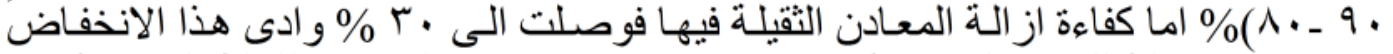

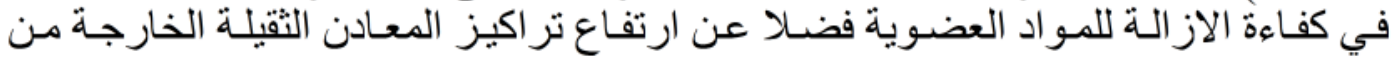


المحطة والتي لا تثماثشى مع المحددات البيئيسة الخاصـة بـالطر ح الى ضـرورة انثـاء معالجـة اضافية للمحطة لتقليل التلوث الحاصل للمستلمات المائية .

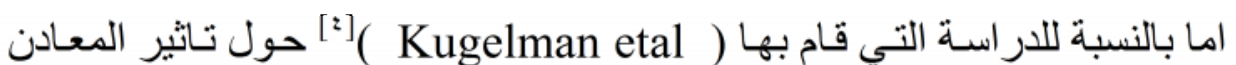

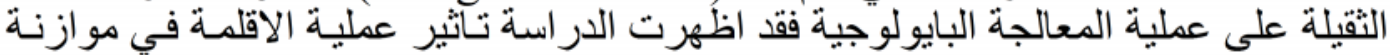

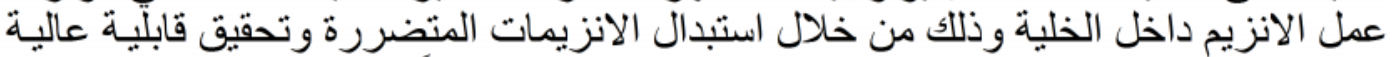

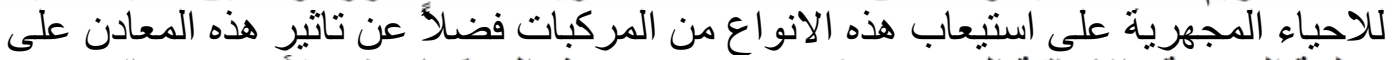

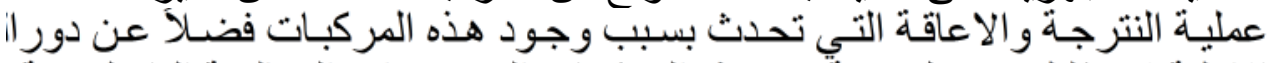

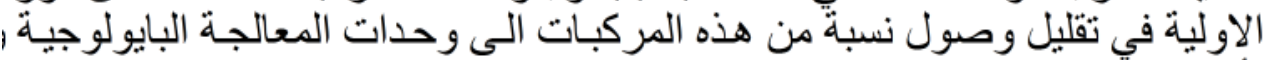
تأثنير ها في تحسين نسبة الاز الة الحاصلة للمو اد العضوية.

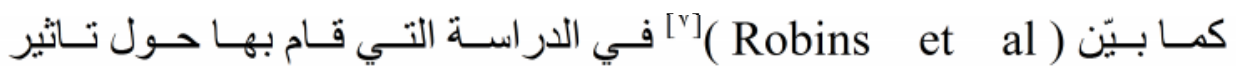

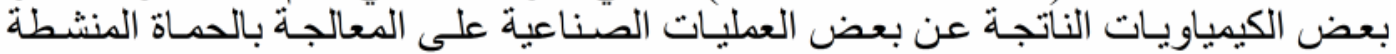

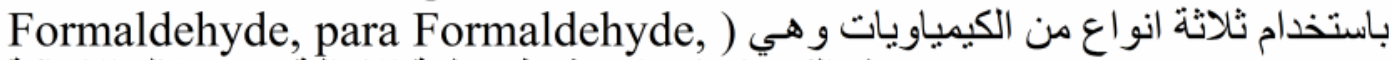
(dimthyliminoethlen

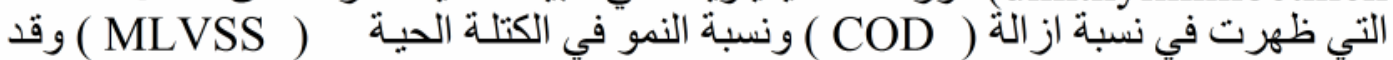

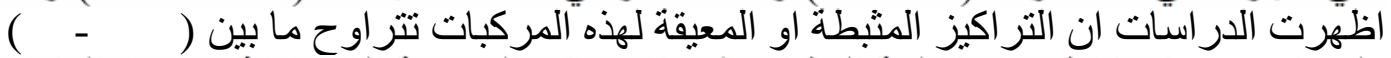

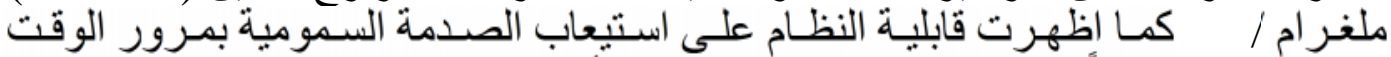

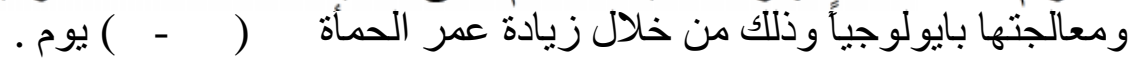

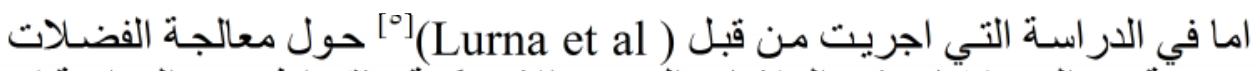

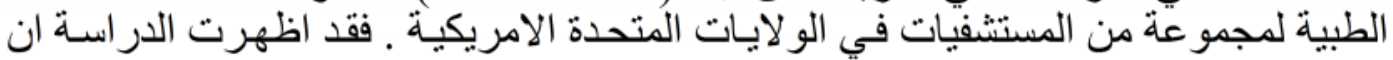

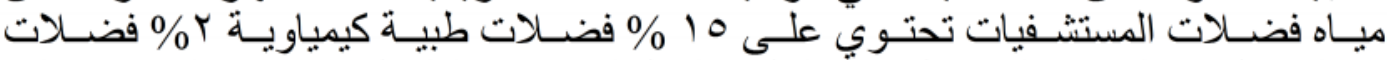

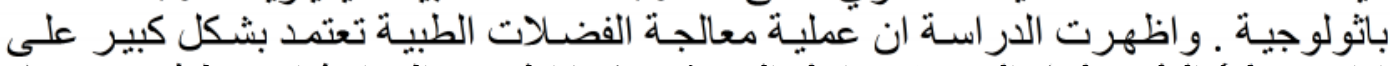

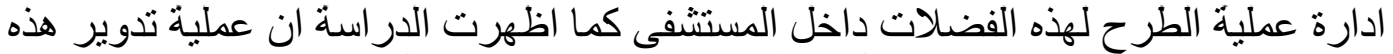

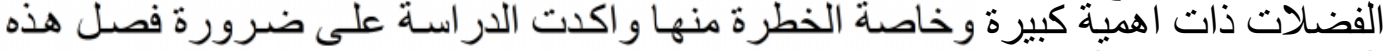

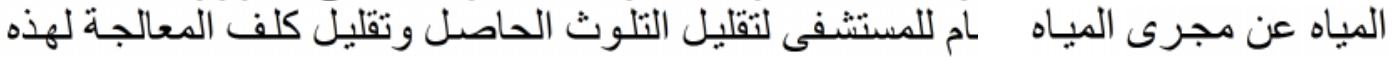

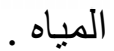

وفي در اسـة اجريت من قبـل The Swedish experience center)

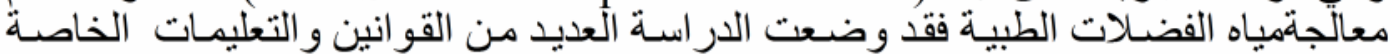

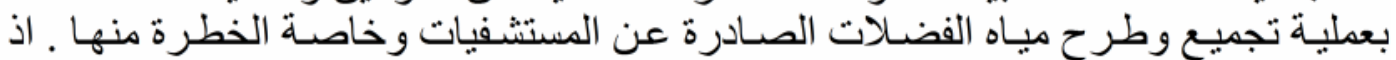

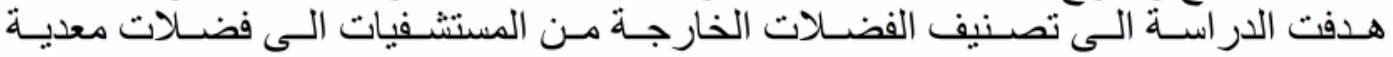

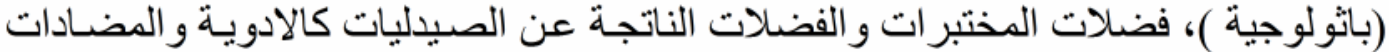

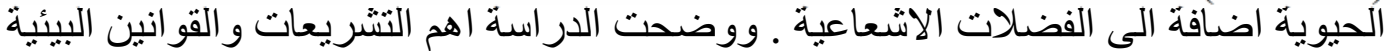

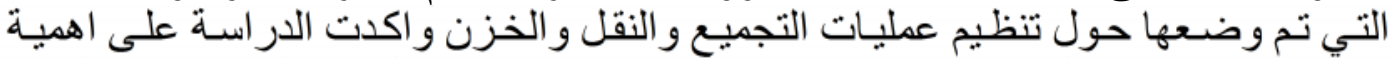

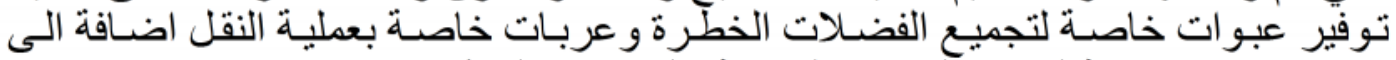

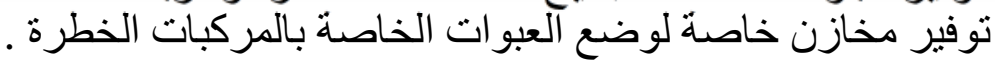

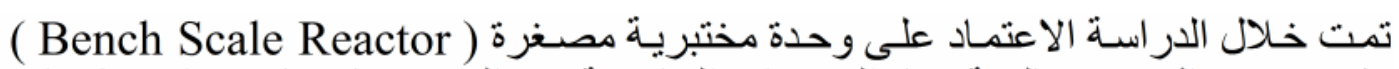

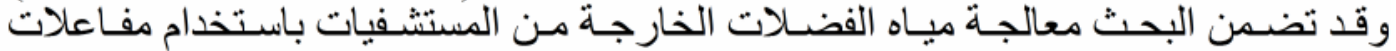

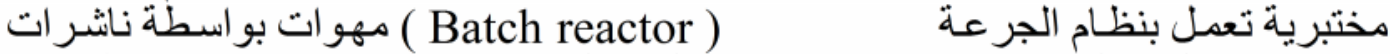
لتحري سرعة از الة الـ ( COD ) والنمو للكتلة الحية وقد تم استخدام حوضين اسطو انيين 
توزيع التهوية بشكل كامل داخل الحوضين وذلك باستخدام ضـاغط هواء ( compressor )

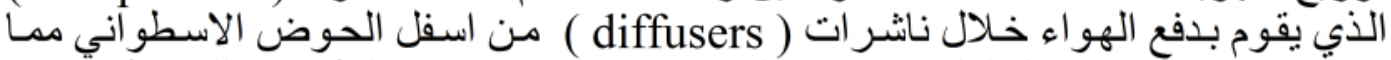

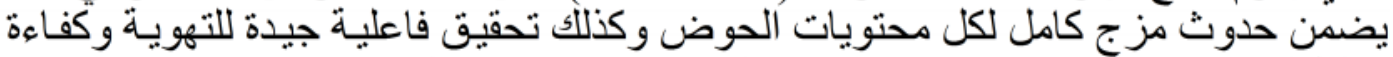

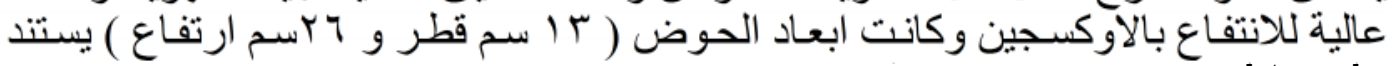

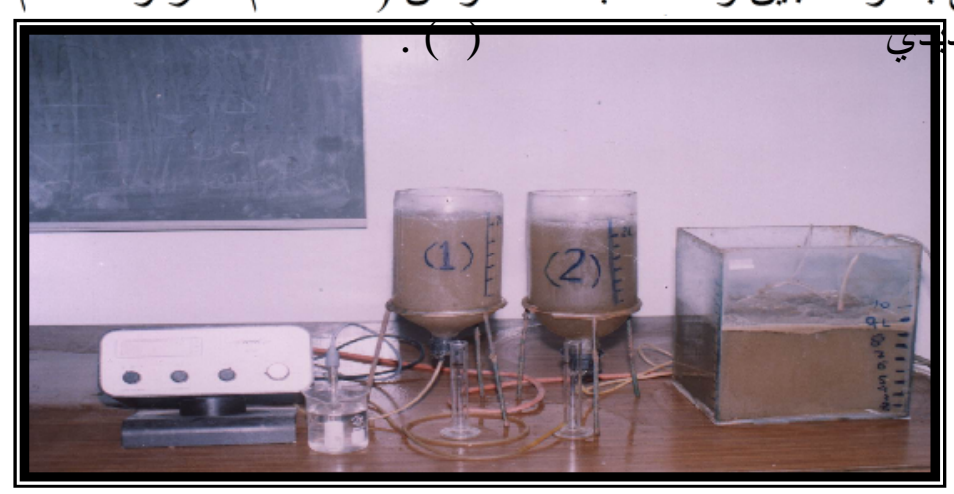

صورة رقم (1) توضح الوحدة المختبرية خلال فترة التفاعل

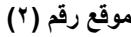

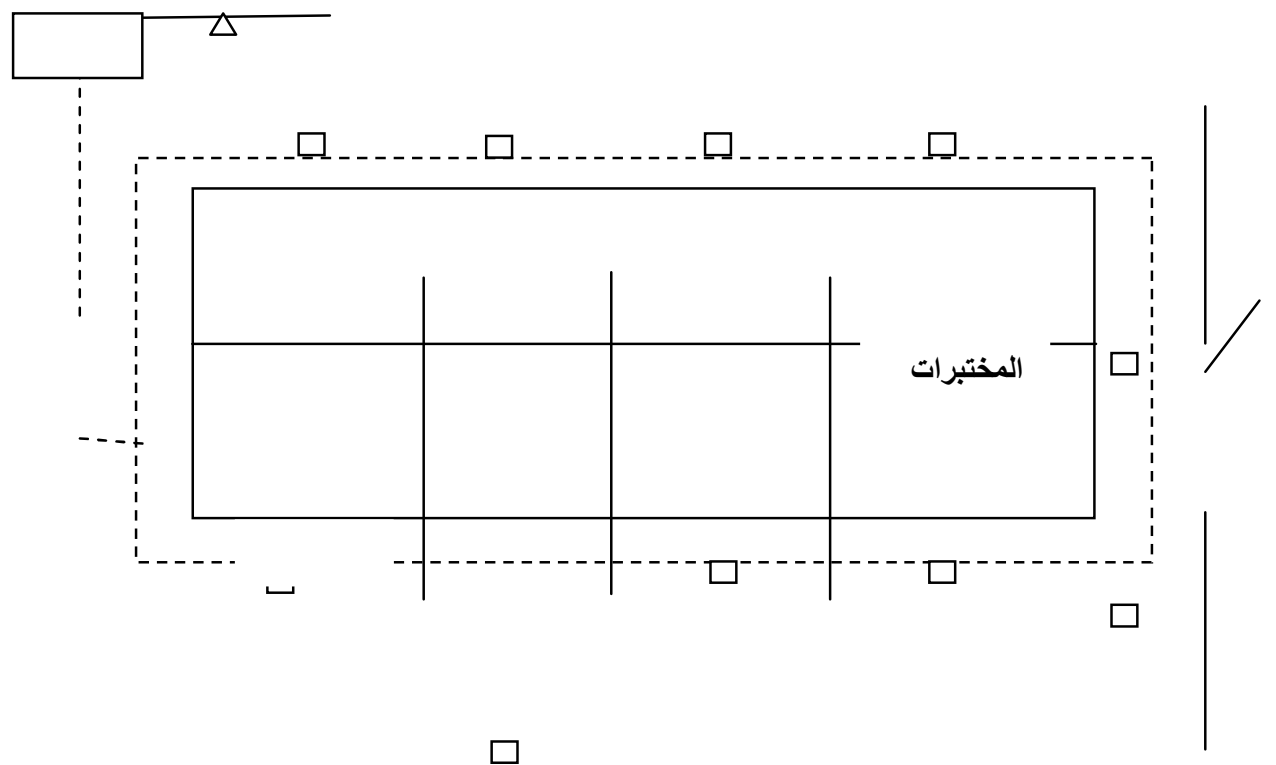

موقع رقم (1) - (1) - م

مخطط يوضح مواقع اخذ النمذجة في مستثفى ابن سينا

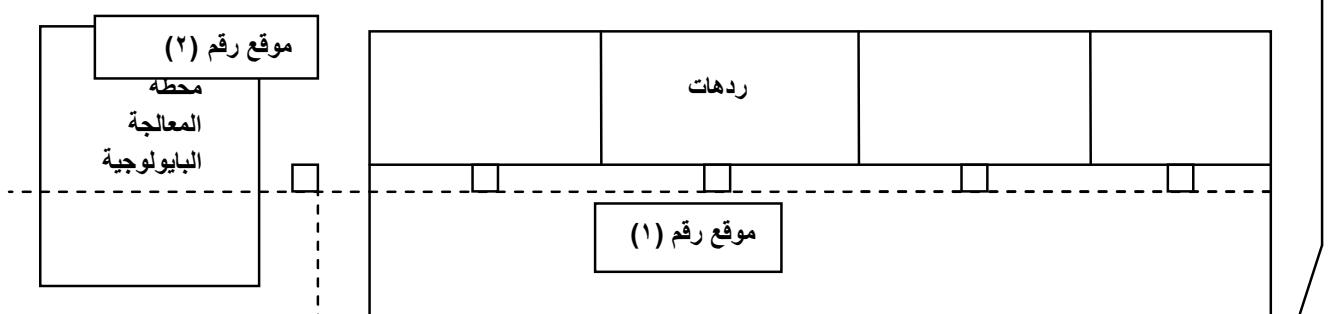


مخطط يوضح مواقع النمذجة في مستشفى الخنساء

M.H

$\square$

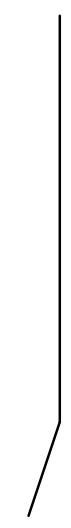

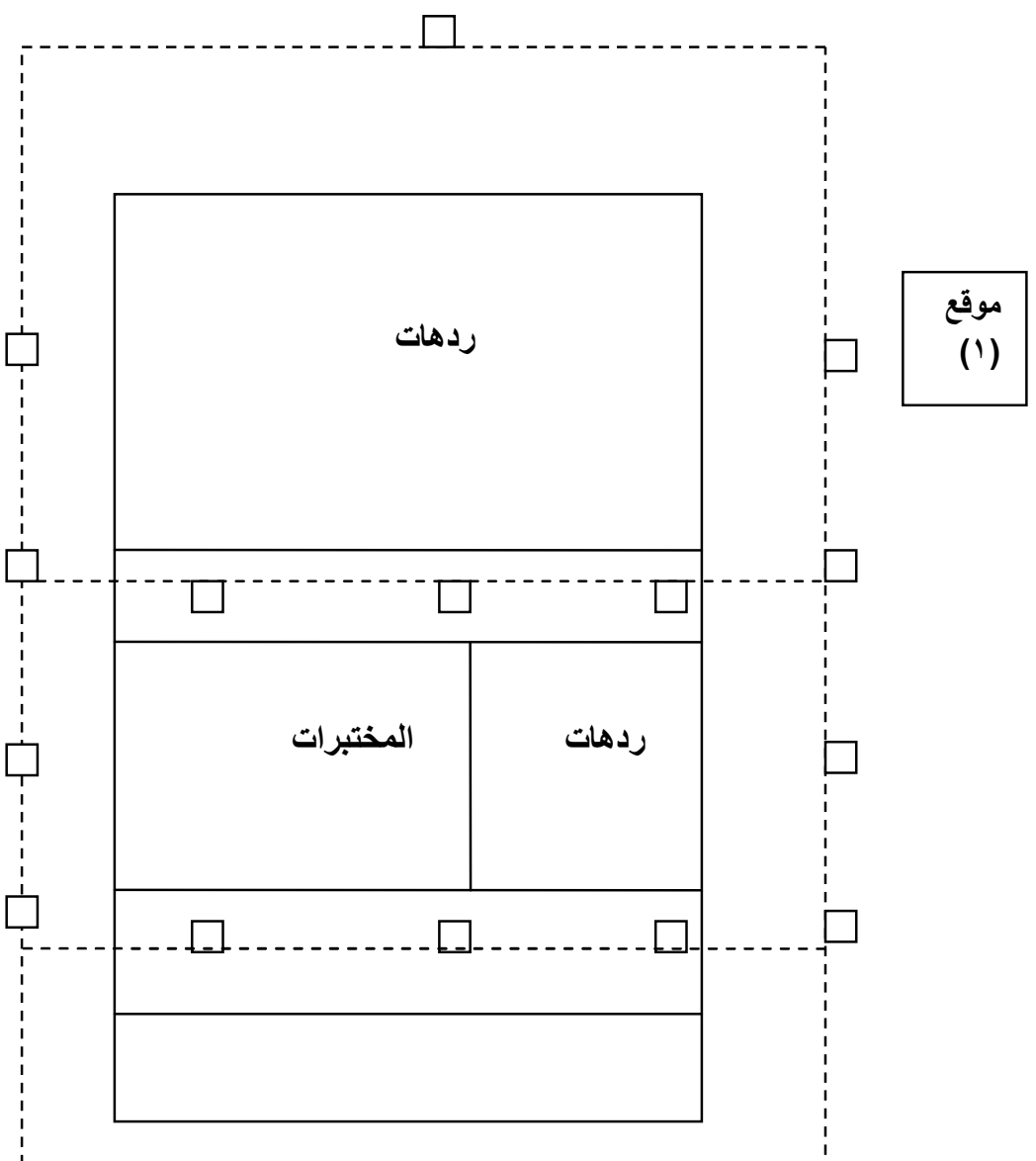




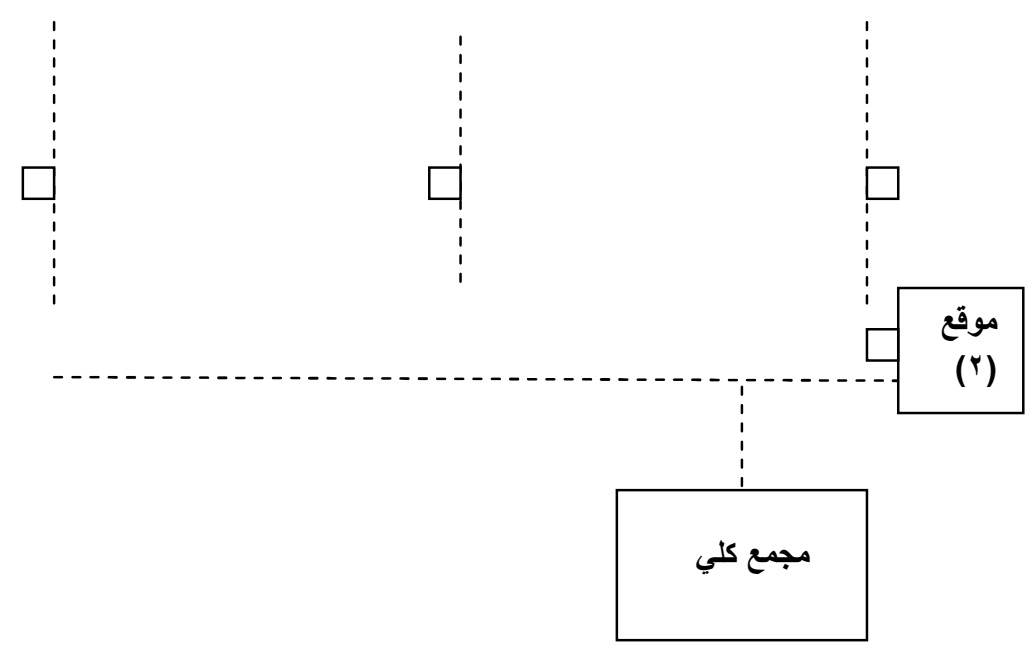

مخطط يوضح مواقع اخذ النمذجة في مستثفى ابن الاثير

\section{M.H}

واجريت عملية النمذجة باخذ عينات مركبة ( Composite Sample ) لتر في كل عملية نمذجة ومن كل موقع برة

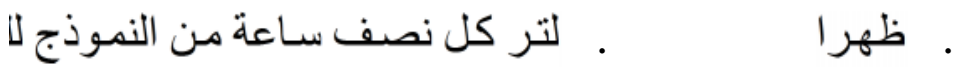

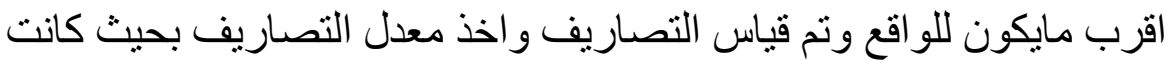

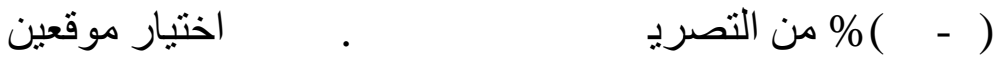

الموقع الاول بمياه فضلات المستشفى غير الممزوجة بكيمياويات المختبر ات حيث يمثل هذا 
الموقع مطروحات معظم الانشطة المختلفة التي تجرى داخل المستشفى منهـا مطرحسات

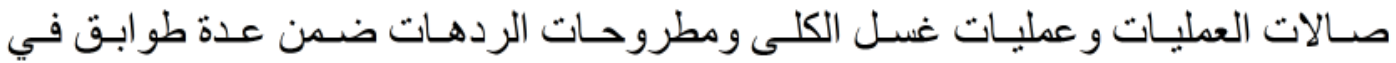

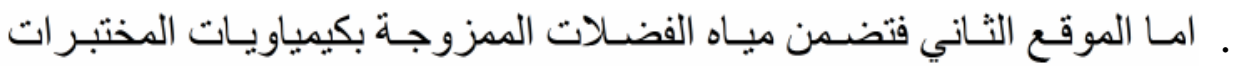

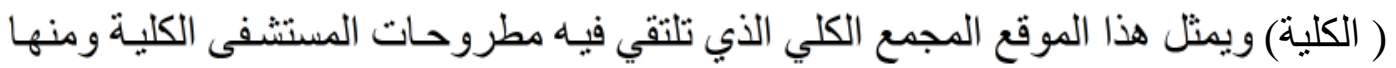

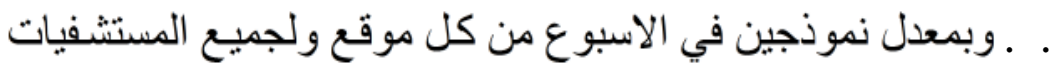

خلال فترة العمل التي استغرقت ستة اشتهر .

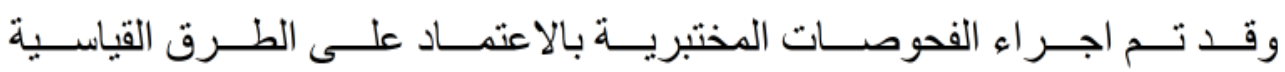
. Standard Methods (APHA, AWWA,WPCF ) ${ }^{[]}$

حيث تم استخدام المحرار الزئبقي الاعتيـادي في : Temperature

جهاز ( pH-meter ) (

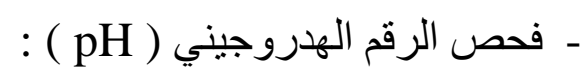

- Eحص التوصيل الكهربائي ( Electrical Conductivity (

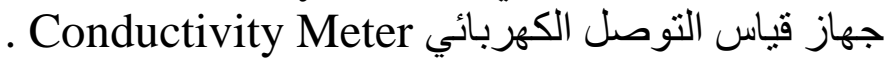

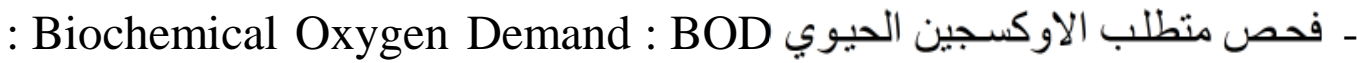

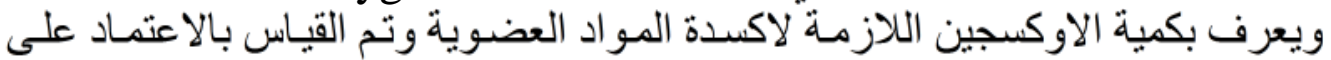

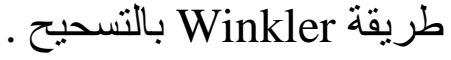

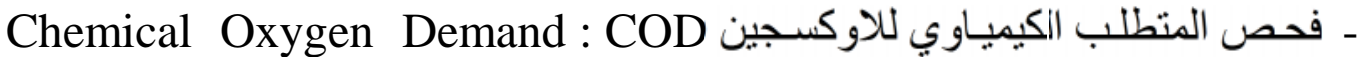
ويعرف بكمية الاوكسجين اللازمة لاكسدة المو اد العضوية كيمياوياوتمت عملية القياس

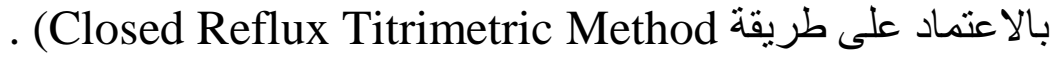

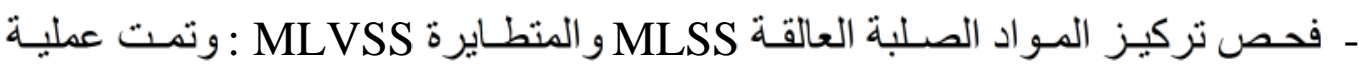

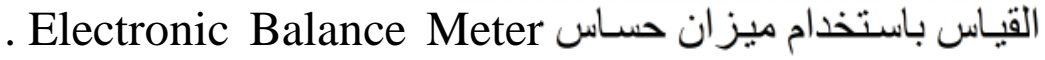

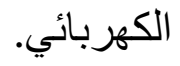
ـقياس معدل استهلاك الاوكسجين OUR : ويعد من الفحوصات المهمة في عملية

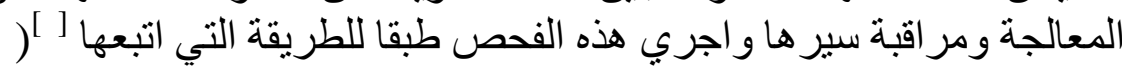

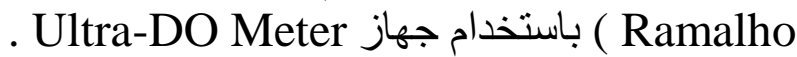

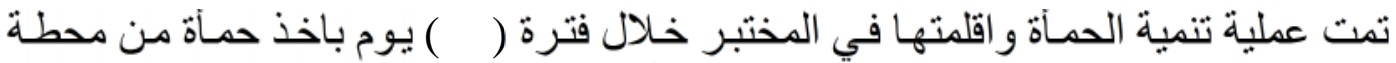

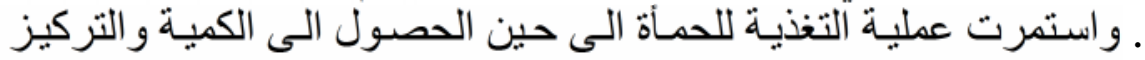

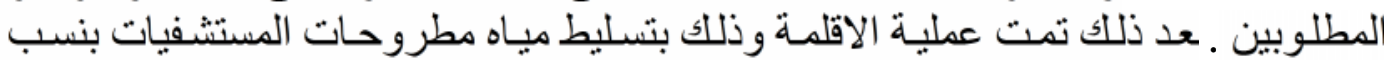
متز ايدة تدريجيا ـ حيث تم اعتماد جزء من هذه الحمة ولمأة في عملية المعالجة .

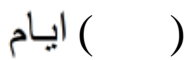

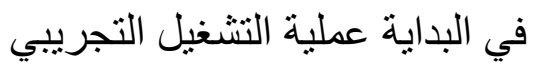

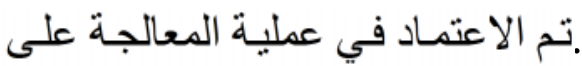
من بدء التشغيل

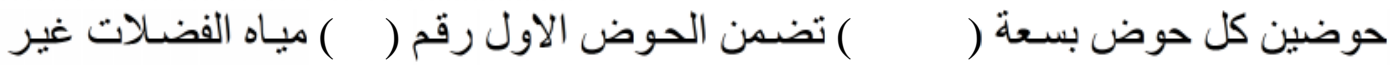

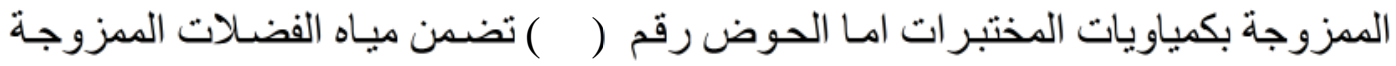

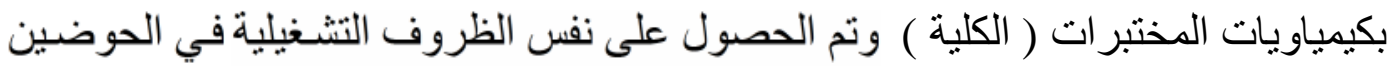

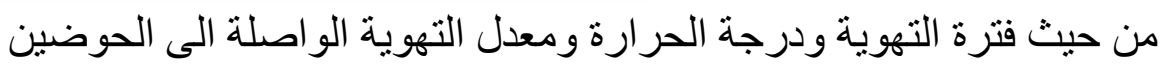

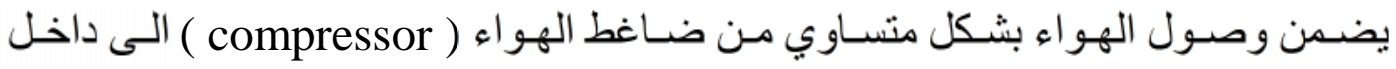


الحوضين.وكانت التهوية كافية بحيث تحقق مز ج كامل لمحتويات الحوضين. وقد تر اوحت

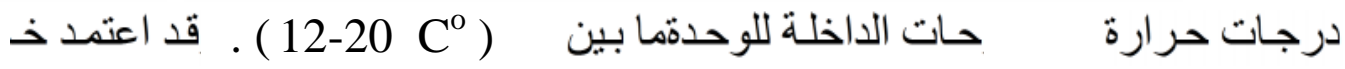

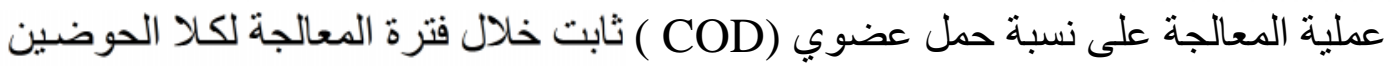

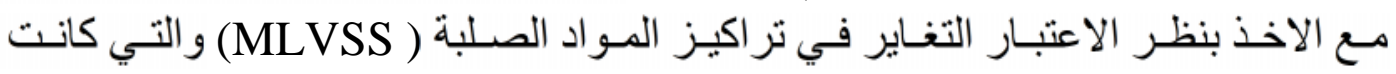
.mg / 1 ( 1000, 1300, 2000, 2500)

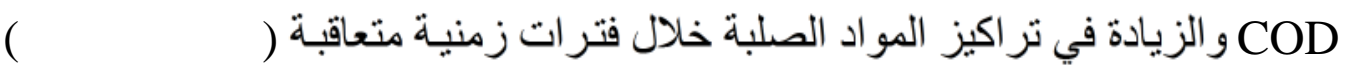

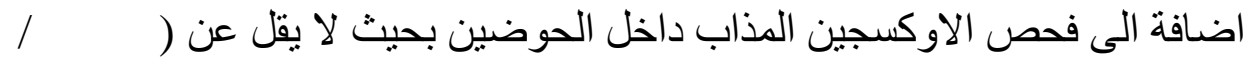

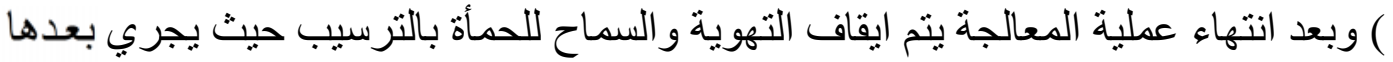

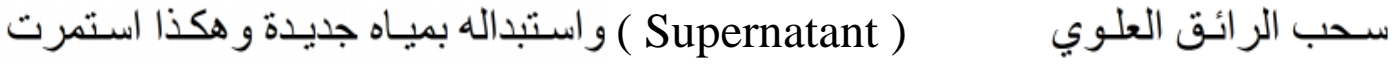

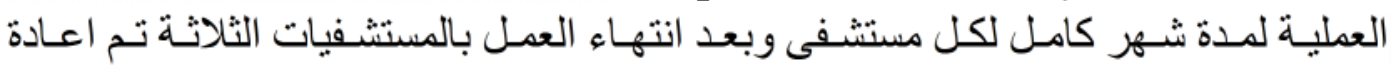
فى وبذلك استغرقت فترة البحث ستة انشهر .

تم التعرف على خصائص المطروحات للموقعين اللاين تم اختيار هـ في المستشفيات

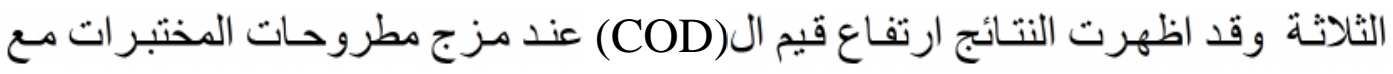

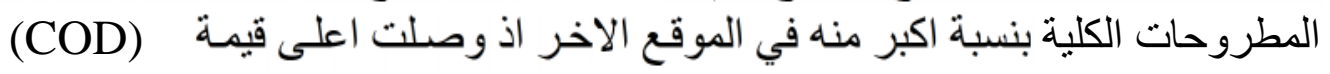

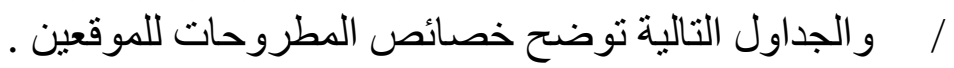

\section{( )}

خصائص مياه الفضلات للموقعين مستشفى ابن سينا

\begin{tabular}{|c|c|c|}
\hline & $(\quad)$ & $(\quad)$ \\
\hline \hline $\mathrm{pH}$ & $6.6-7.6$ & $6.8-8.1$ \\
\hline E. C $\mu \mathrm{hos} / \mathrm{cm}$ & $995-1970$ & $1050-2470$ \\
\hline Temp ${ }^{\mathbf{C}} \mathrm{C}$ & $12-20$ & $12-20$ \\
\hline BOD5 mg/l & $125-430$ & $150-375$ \\
\hline COD mg/l & $250-630$ & $300-1200$ \\
\hline T.S mg/l & $1120-2360$ & $1230-2510$ \\
\hline S.S mg/l & $36-140$ & $60-180$ \\
\hline
\end{tabular}




\section{( يتضمن مياه الفضلات للمستشفى غي}

( يتضمن مياه الفضلات للمستشفى الممزوجة بفضلات المختبر ( الكلية )

$$
\text { * تراوحت نسبة تصريف مياه المختبر الى التصريف الكلي ( - ) }
$$

\begin{tabular}{|c|c|c|}
\hline \multirow{2}{*}{ 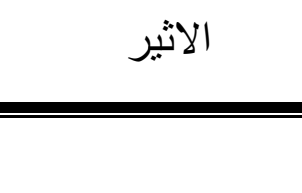 } & \multicolumn{2}{|c|}{ خصائص مياه الفضلات للموقعين } \\
\hline & () & ( ) \\
\hline pH & $6.2-8$ & $6.8-8.1$ \\
\hline E. C $\mu$ hos $/ \mathrm{cm}$ & 1300-1780 & $950-2300$ \\
\hline $\operatorname{Temp}^{\circ} \mathrm{C}$ & $12-20$ & $12-20$ \\
\hline BOD5 mg/l & $190-430$ & $210-375$ \\
\hline COD mg/l & $210-500$ & $330-1100$ \\
\hline T.S mg/l & $1200-2430$ & $1340-2730$ \\
\hline S.S mg/l & $160-215$ & $190-320$ \\
\hline
\end{tabular}

( ينضمن مياه الفضلات للمستشفى غير المزورجة بفضلات المختبر

( يتضمن مياه الفضلات للمستشفى الممزوجة بفضلات المختبر ( الكلية )

$$
\text { *تراوحت نسبة تصريف مياه المختبر الى التصريف الكلي ( - ) }
$$

$$
\text { خصائص مياه الفضلات }
$$

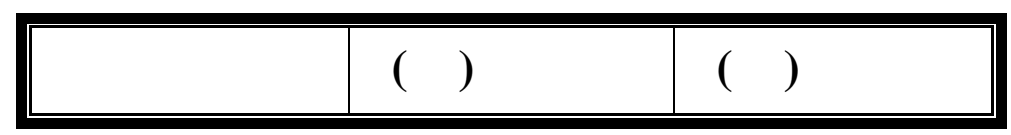




\begin{tabular}{||c|c|c||}
\hline EH & $6.4-7.53$ & $7.3-8.2$ \\
\hline E. C $\mu$ hos $/ \mathrm{cm}$ & $350-730$ & $530-1125$ \\
\hline Temp ${ }^{\circ} \mathrm{C}$ & $12-20$ & $12-20$ \\
\hline BOD5 mg/l & $190-430$ & $210-460$ \\
\hline COD mg/l & $280-820$ & $320-1250$ \\
\hline T.S mg/l & $730-1500$ & $890-1800$ \\
\hline S.S mg/l & $169-198$ & $310-680$ \\
\hline
\end{tabular}

( ) يتضمن مياه الفضلات للمستشفى غير المززوجة بفضلات المختبر

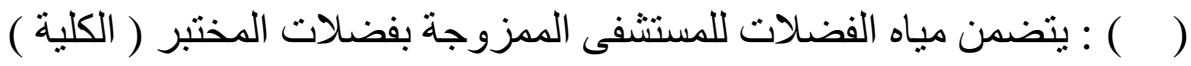
* تراوحت نسبة تصريف مياه المختبر الى التصريف الكلي ( - ) )

\section{خصائص المعالجة البايولوجية :}

( COD ) و النمو للكتلة الحية ( MLVSS ) ومعدل استهلاك الاوكسجين

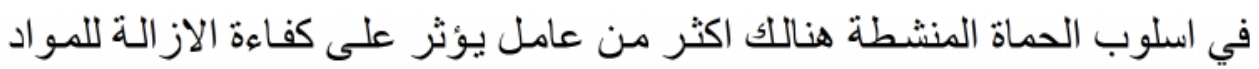

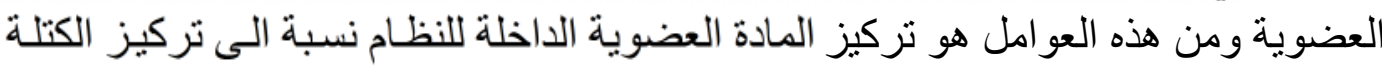

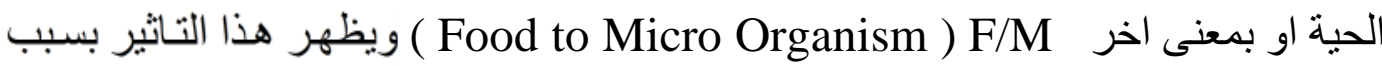

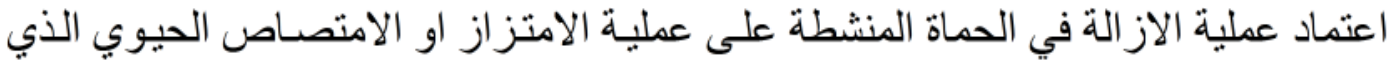
F/M البدائية الداخلة الألة

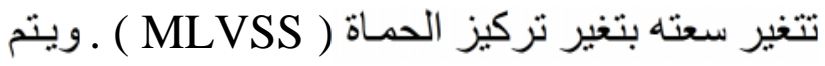

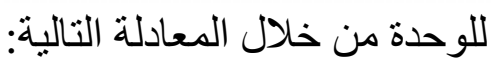

$$
\mathrm{F} / \mathrm{M}=\mathrm{S}_{0} / \mathrm{X}
$$

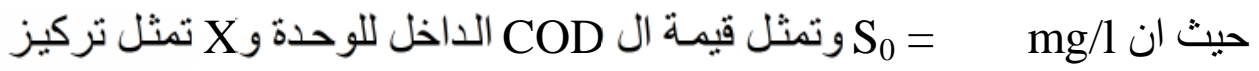

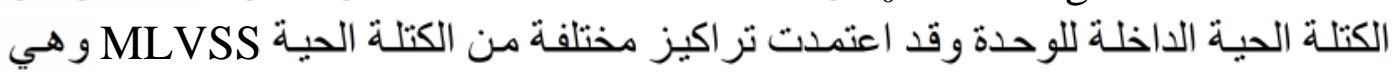

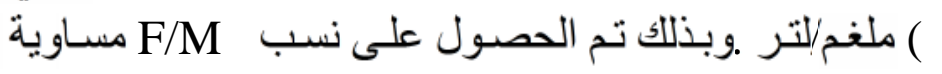

$$
\text { ( . . . . . . ) }
$$

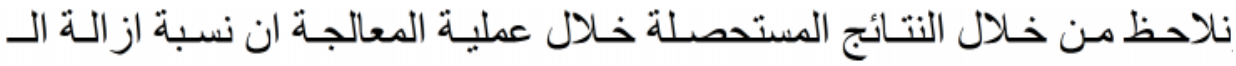

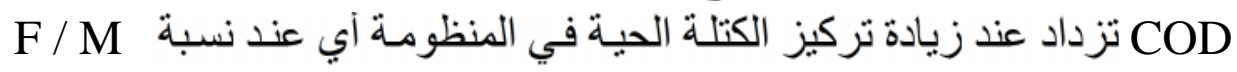

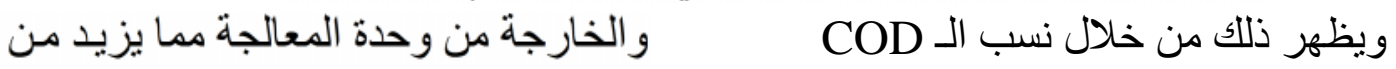

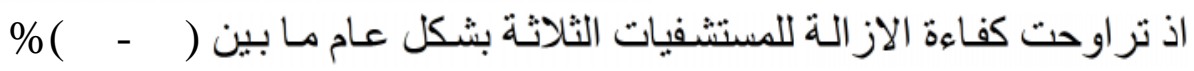

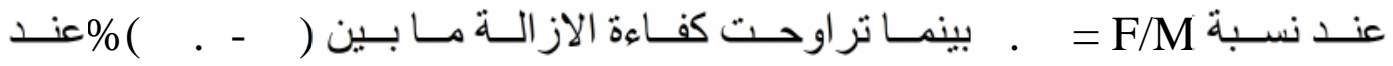
. " ] وهذا ما اكده F/MenFelder ) " 


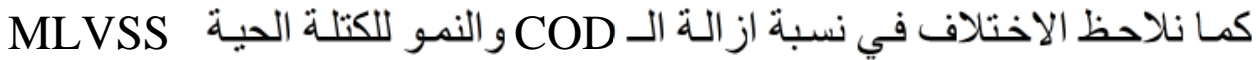

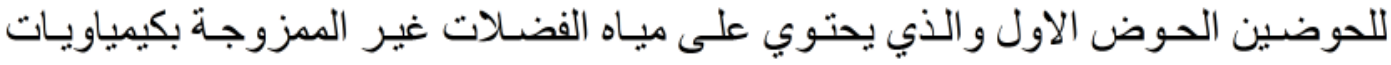

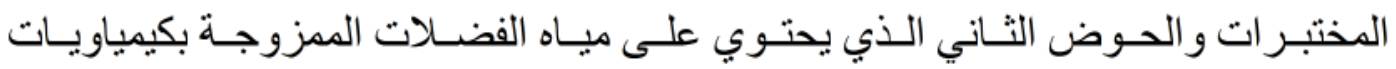

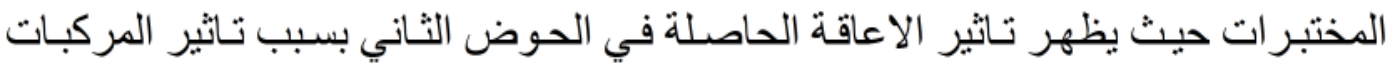

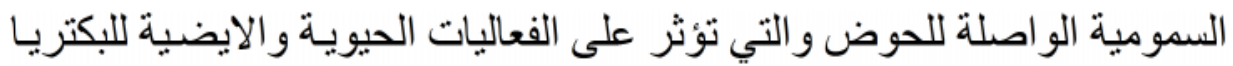

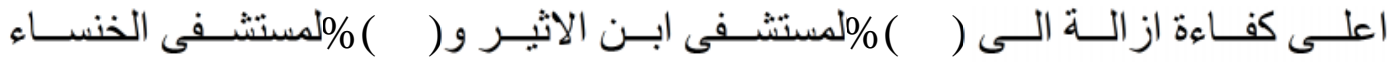

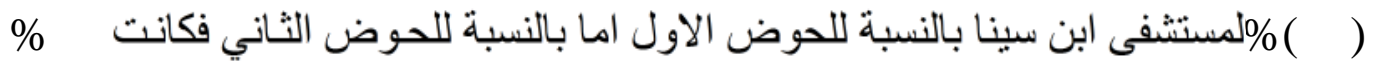

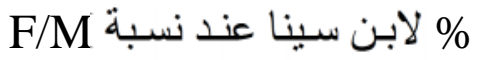

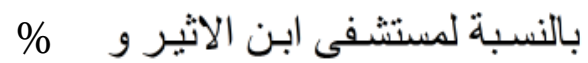

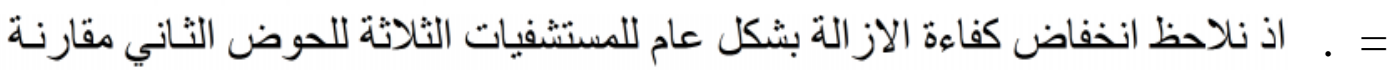
Gaudy

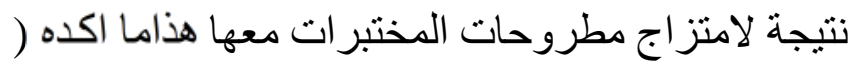

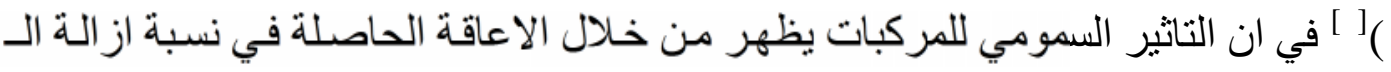

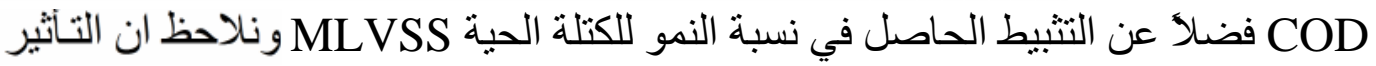

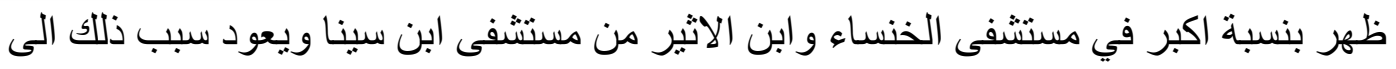

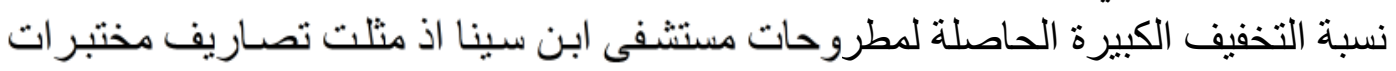

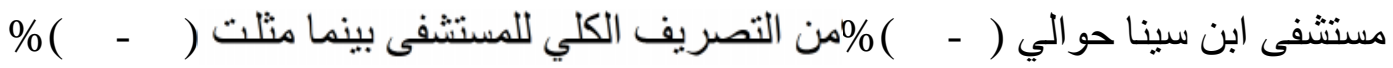

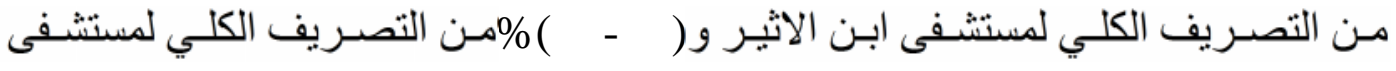
$(-)$

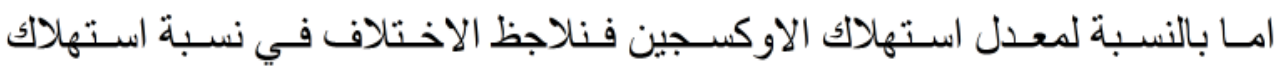

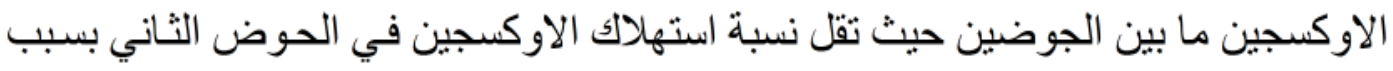

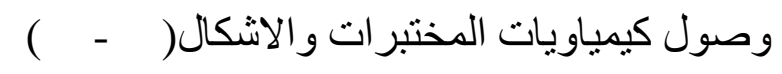

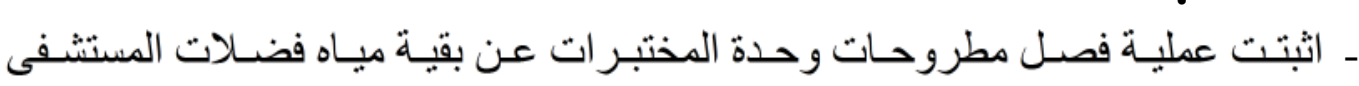

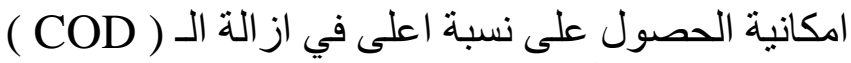

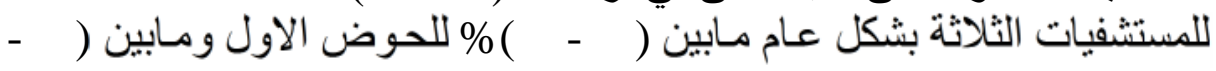
$\%($

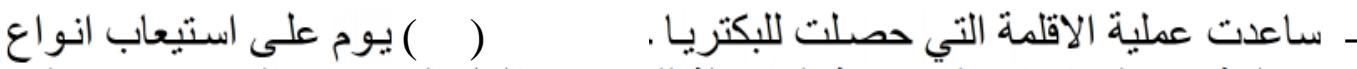

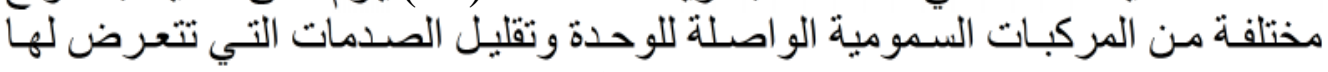

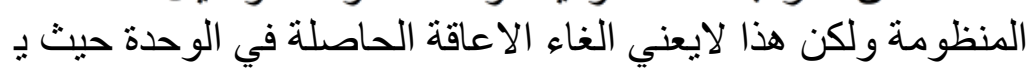

ـاثتتت عملية الاز الة البايولوجية بالاعتماد على نس F/M مختلفة ان كفاءة الاز التة تعتمد

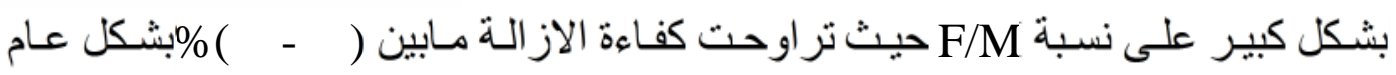

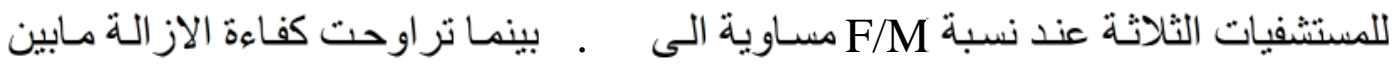

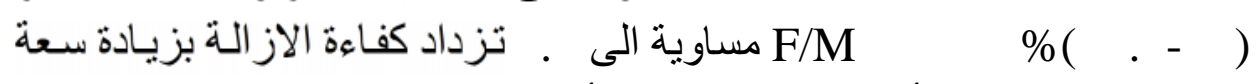

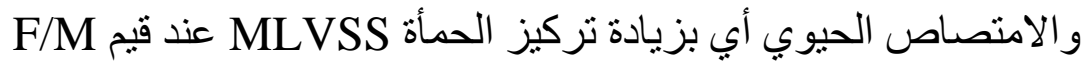


ـ تؤدي عملية مزج مطروحات المختبر ات بما تحتويه من مركبات كيمياوية وسموميات مع

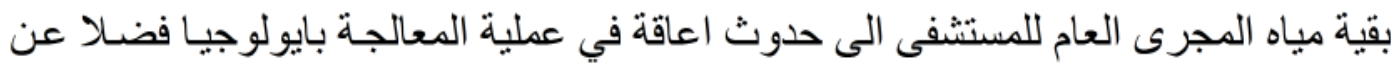

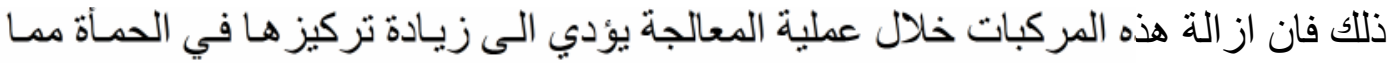

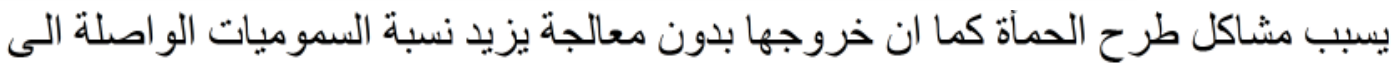




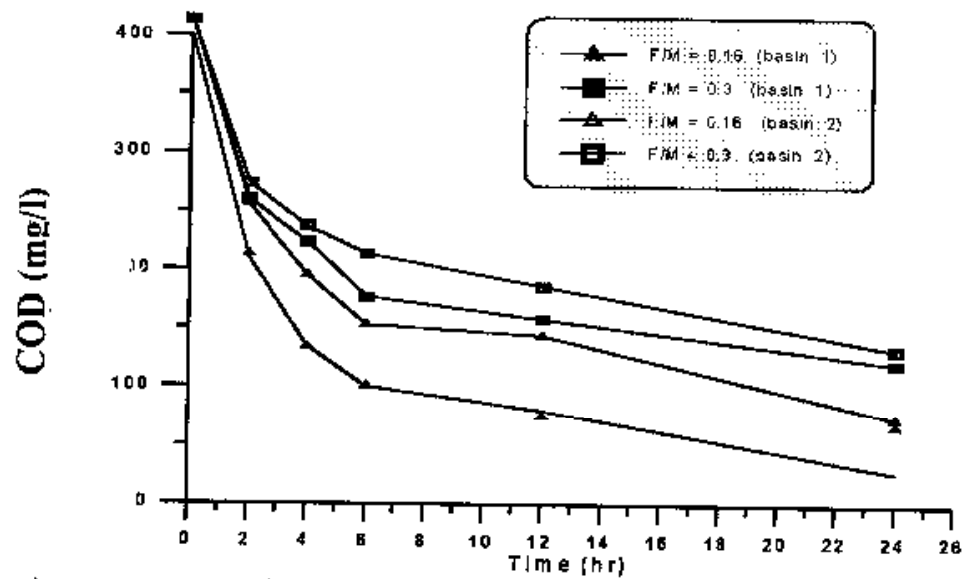

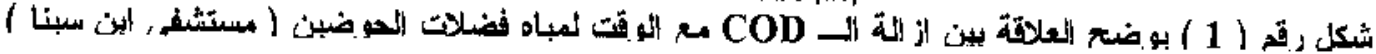

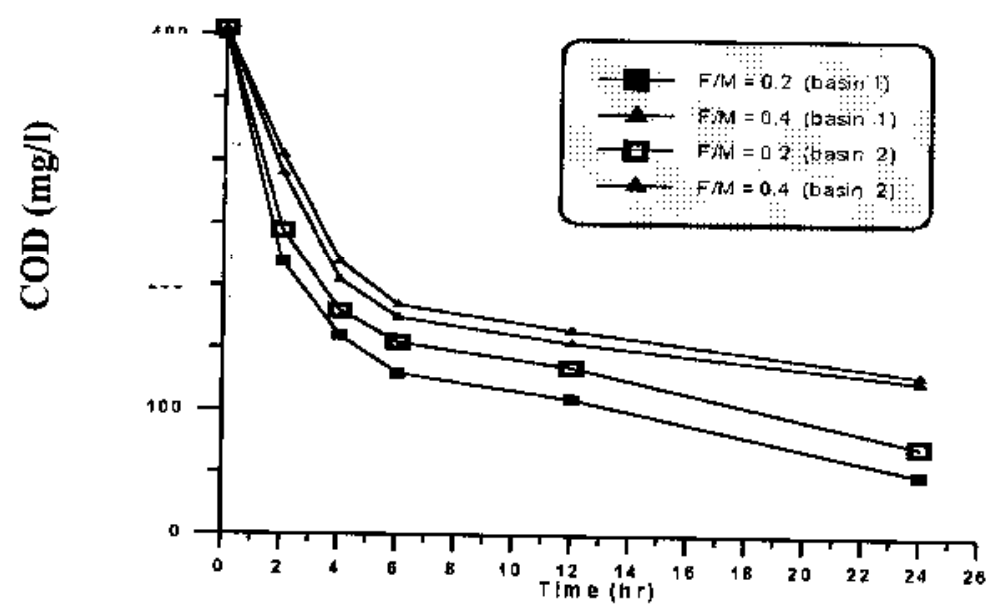

شكل رقت (2) العلاقة بين ازيالة الــ COD مع ألوقت لعياه فضلات الحوضين ( مستشفى ابن سينا )

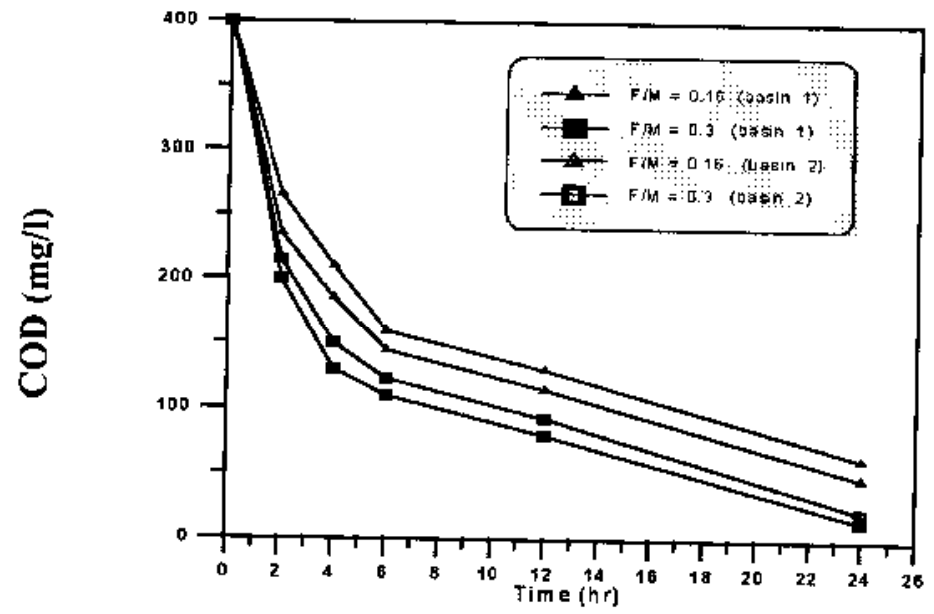

شكل رقم (3) العلاقة بين ازائة بـ COD مي الوقت لمياه فضلات الحوضين ( مستثفى ابن الأمير ) 


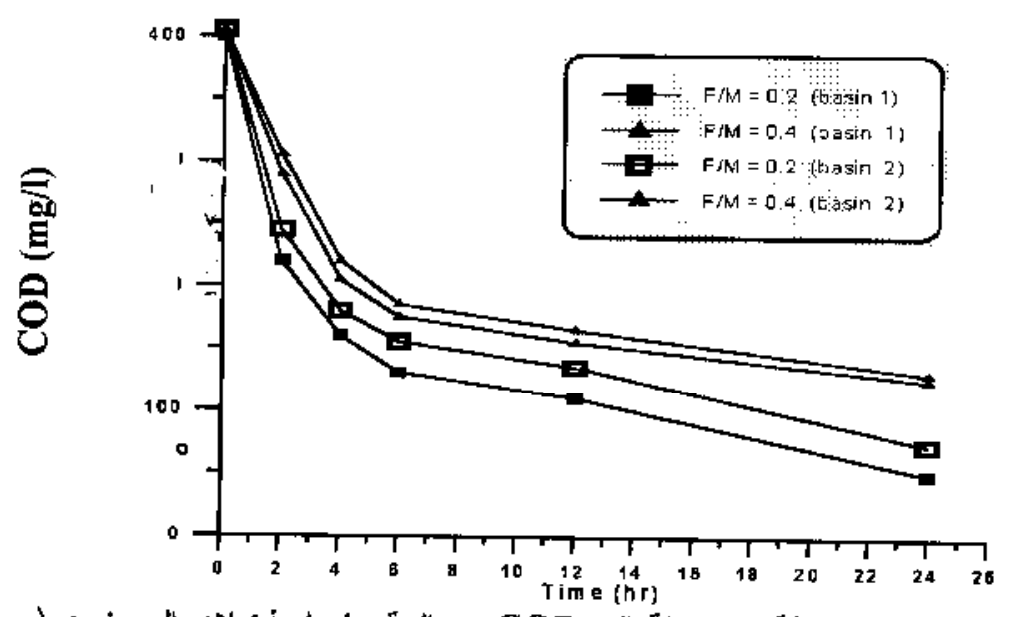

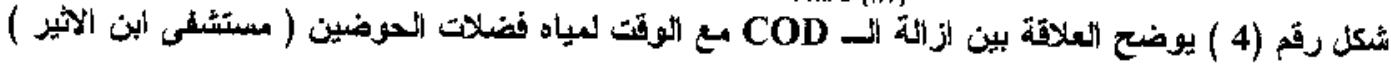

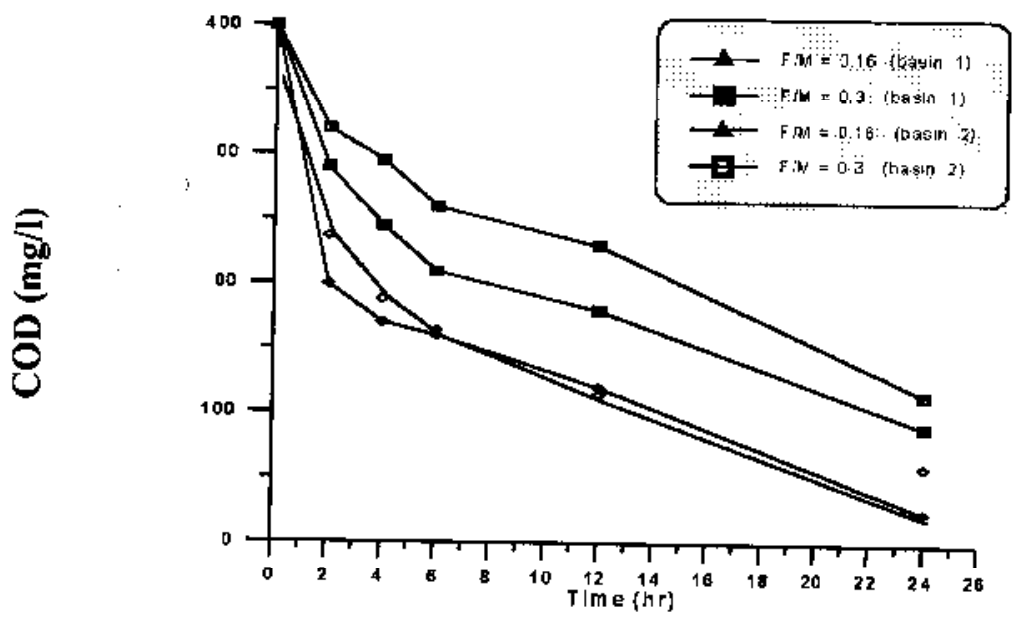

شكل رقم ( 5 ) يوضع العلاتة بين ازائة الـ COD مع الوقت لمياه فضلات الموضين ( مستشفى الخنساء )

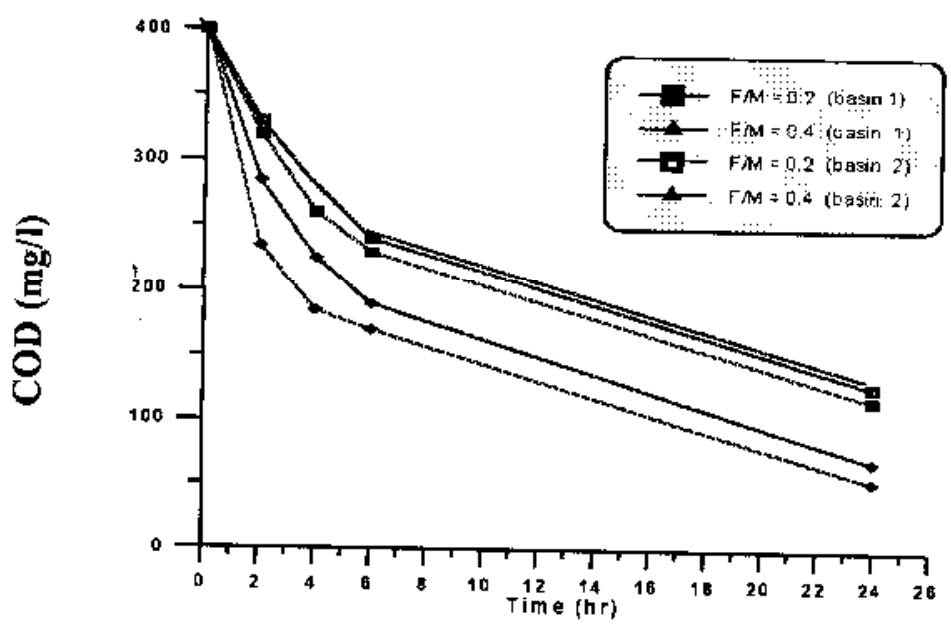

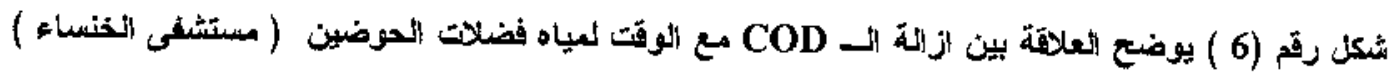




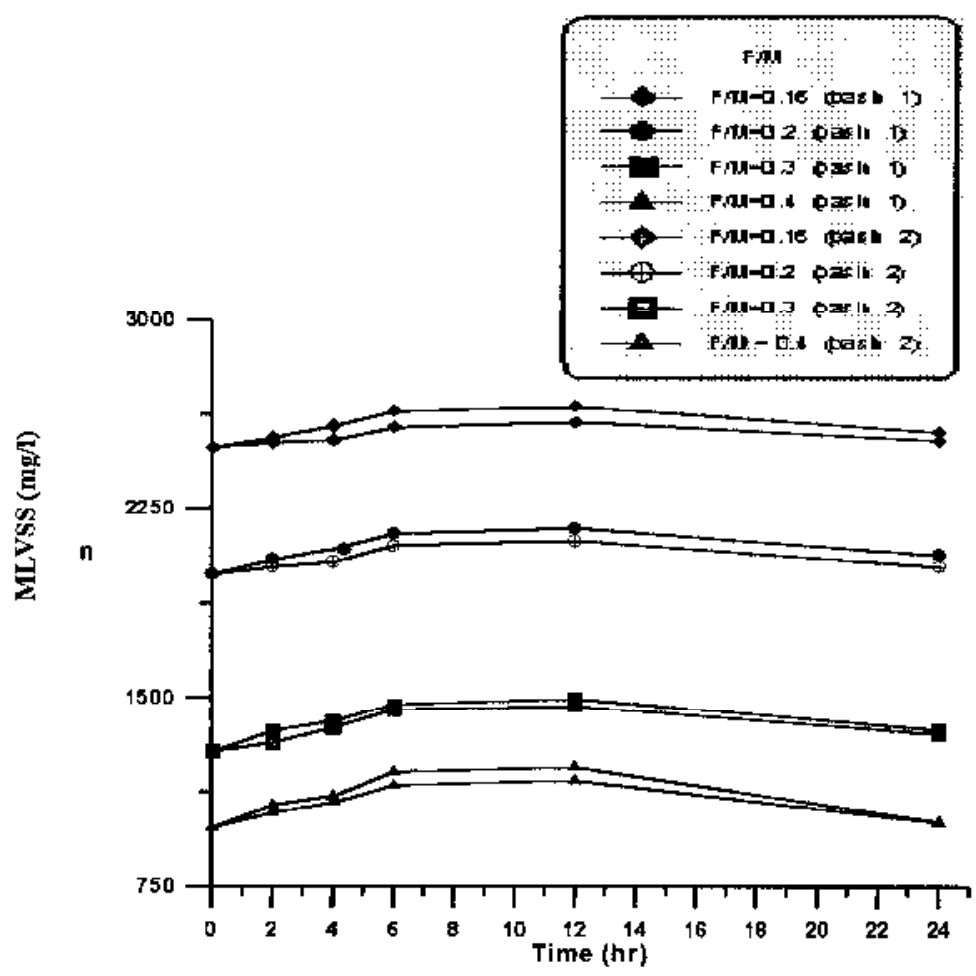

شكل رثم (7) يوضتح العلاقة بين نسبة النمو للكثلة الحية MLVSS ميع الوقت لمياه فضلات ألحوضين

(مستشفى ابن سينا )

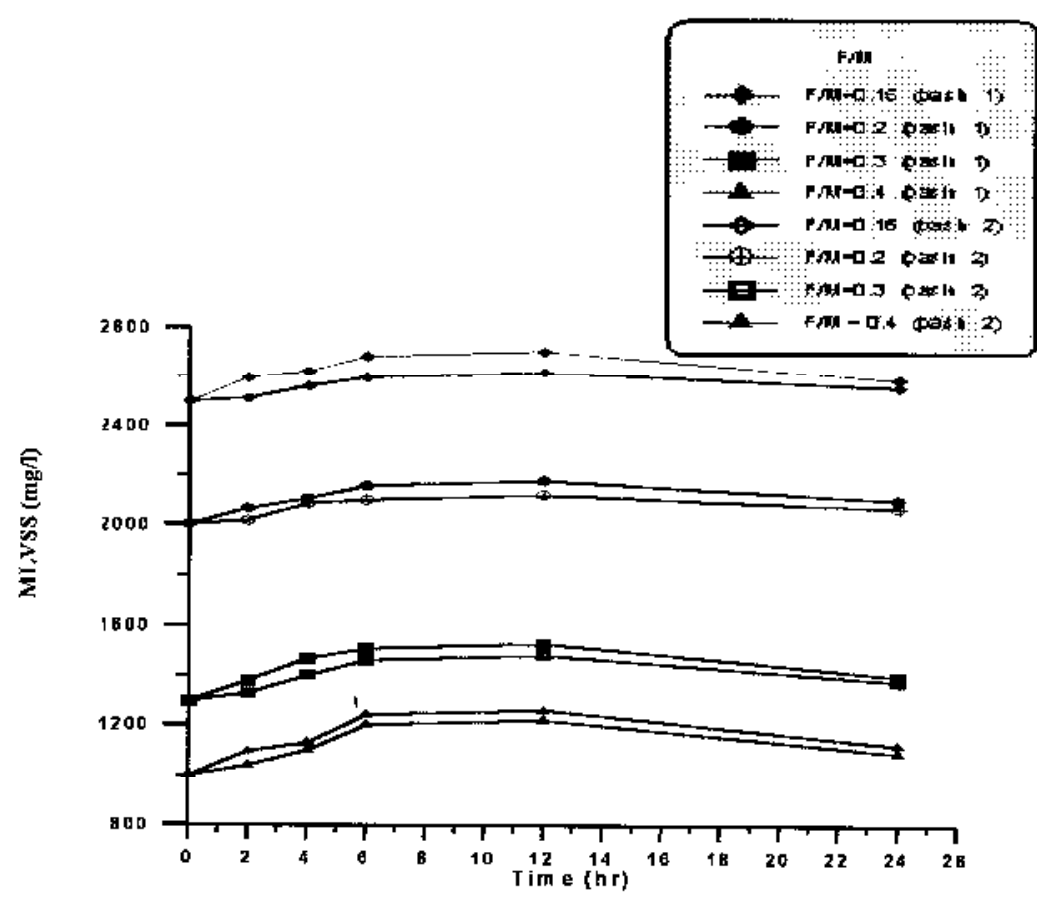

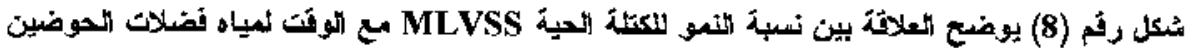

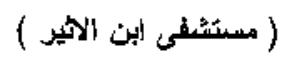




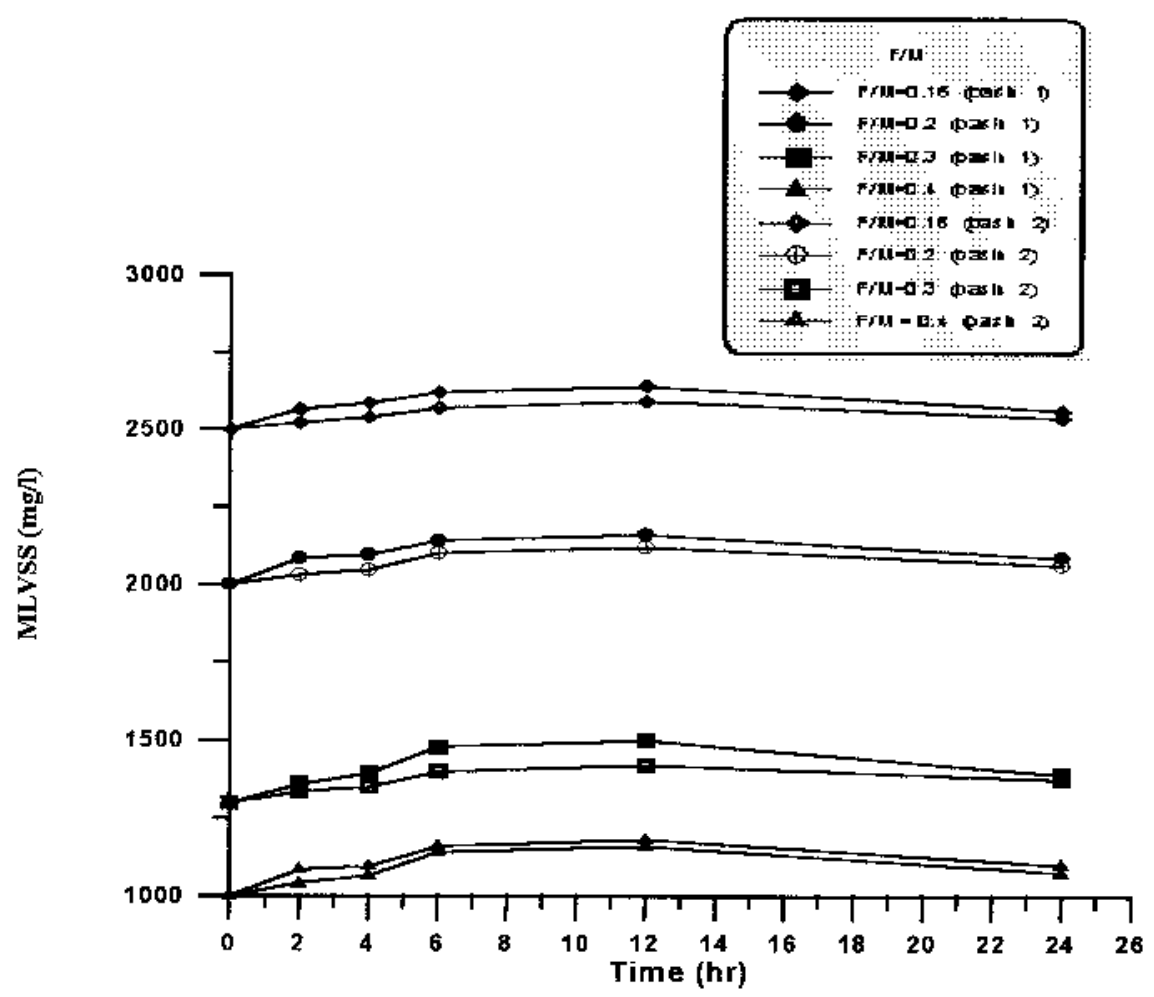

شكل رقم ( 9 ) يوضح العلاقة بين نسبة النمو للكتة الحية MLVSS مع الوقت لمياه فضلات اللحوضين

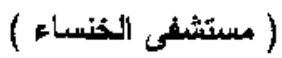

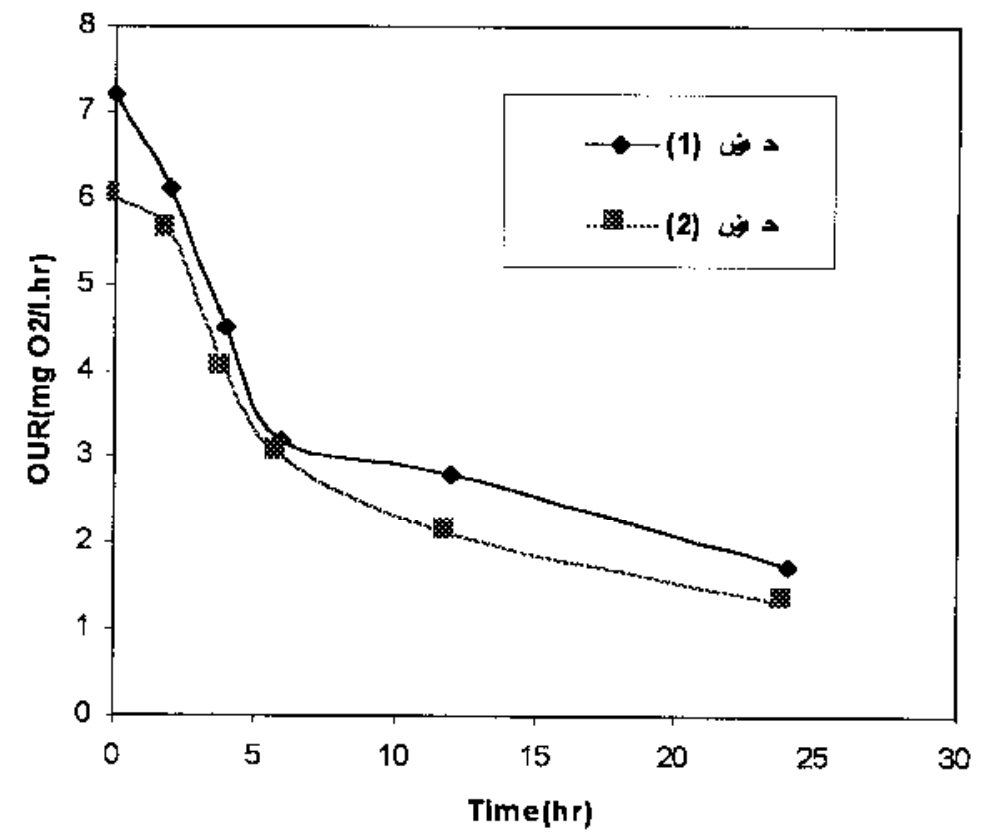

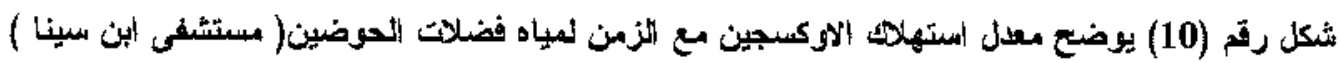




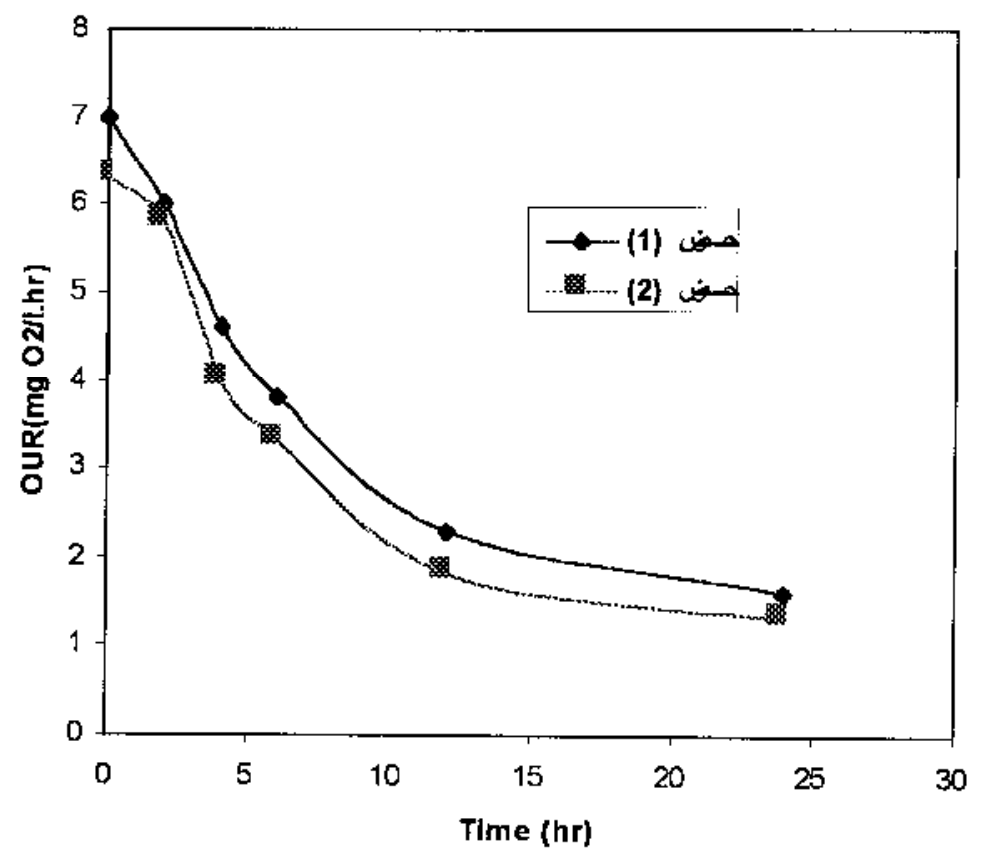

شكل رقم (11) يوضح معدل استهلاد الالوكسجين ميع الززمن لعياه أضلات الحوضين ( مستشفى ابن الأثيز )

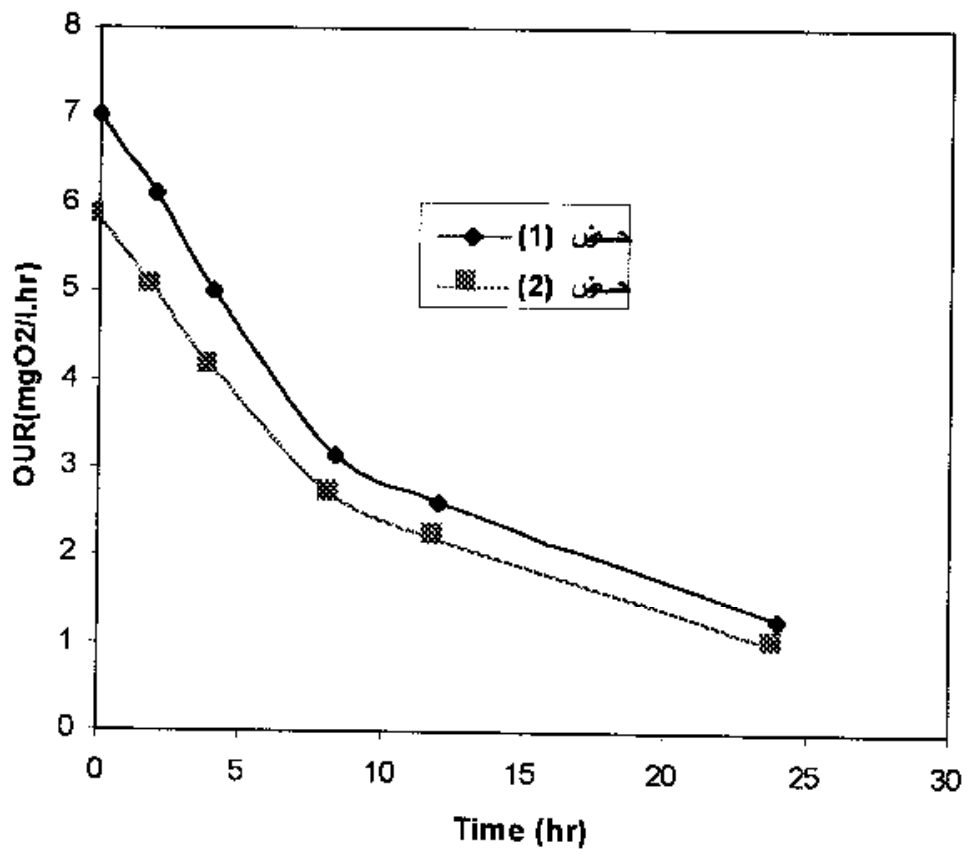

شكل رقم (12) يوضتح معدل استهلها الأوكسجين ميع الززمث أمياه فضلات الحوضين( مستشفى الخنساء ) 


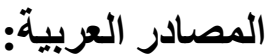

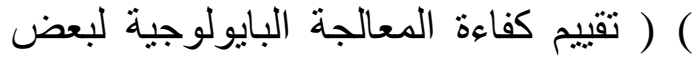

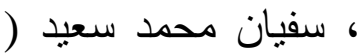

الدليمي ،

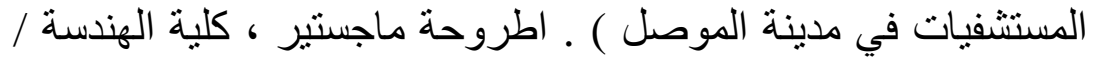

)$(\quad)$

معالجة مياه مطروحات المستشفيات ) اطروحة ماجستير ، كلية الهذ /

) الهندسة العملية للبيئة فحوصات

(باوي ، سعاد عبد وحسن ، محمد سليمان

صادر الاجنبية: - n n

1 EckenFelder, W.W. (1999) (Industrial water pollotion control), McGraw, New York, 218-234.

2 Junko, K. \& Shoich, K. (1972) (Some problems on the joint treatment of Industrial and sewage in the Ukima treatment plant), Water Research, 7, 375-384. University of Tokyo, Japan.

3 Kugelman, I.J. \& Carty, P.L. (1974) (Cation toxicity and Simulation in anaerobic waste treatment) 19th ((Industrial waste Conference)).,USA. 667.

4 Laura, B. \& Rob, C. (2000) (Medicalwaste treatment technologies), Health care without harm, The company for environmentally reponsible Health care).

www.noharm.org/nonincineration

5 Romalho, R.S. (1977) (Introduction to wastewater treatment process), (Academic press), Inc., Canada, 164-205. 
محمود: تأثيركيمياويات مطروحات مختبرات المستشفيات على كفاءة المعالجة البايولوجية لمياه الفضلات

6 Robins, J. H. \& Green, A.C. (1974) (Development one share treatment system for sewage from water craft waste retention system). J. WPCF, 53, 12.

7 Standard Methods for Examination of Water and wasteWater. 16th ed., Am. Public Healthy Assoc. Washington D.C. (1985).

8 The Swedish experience center, (2003), (Swedish system of handling clinical waste), Green market, Sweden.

www.ene.gov.on.ca/envision/gp/6388e.htm

9 Winkler, M.A. (1981) (Biological treatment of wastewater), 1st, New York, USA, 118-144. 